\title{
Comparative analysis of the Corynebacterium glutamicum group and complete genome sequence of strain $\mathrm{R}$
}

\begin{abstract}
Correspondence
Hideaki Yukawa

mmg-lab@rite.or.jp
\end{abstract}

Received 23 October 2006

Revised 19 December 2006

Accepted 2 January 2007

\author{
Hideaki Yukawa, ${ }^{1,2}$ Crispinus A. Omumasaba, ${ }^{1}$ Hiroshi Nonaka, ${ }^{1}$ \\ Péter Kós, ${ }^{1}+$ Naoko Okai, ${ }^{1}$ Nobuaki Suzuki, ${ }^{1}$ Masako Suda, ${ }^{1}$ Yota Tsuge, ${ }^{1,2}$ \\ Junko Watanabe, ${ }^{1}$ Yoko Ikeda, ${ }^{1}$ Alain A. Vertès ${ }^{1}$ and Masayuki Inui ${ }^{1}$ \\ ${ }^{1}$ Microbiology Research Group, Research Institute of Innovative Technology for the Earth \\ (RITE), Soraku, Kyoto 619-0292, Japan \\ ${ }^{2}$ Graduate School of Biological Sciences, Nara Institute of Science and Technology, Ikoma, \\ Nara 630-0101, Japan
}

\begin{abstract}
The complete genome sequence of Corynebacterium glutamicum strain $\mathrm{R}$ was determined to allow its comparative analysis with other corynebacteria. The biology of corynebacteria was explored by refining the definition of the subset of genes that constitutes the corynebacterial core as well as those characteristic of saprophytic and pathogenic ecological niches. In addition, the relative scarcity of corynebacterial sigma factors and the plasticity of their two-component system machinery reflect their relatively exacting nutritional requirements and reduced membraneassociated and secreted proteins. The conservation of key genes and pathways between corynebacteria, mycobacteria and Nocardia validates the use of C. glutamicum to study fundamental processes that are conserved in slow-growing mycobacteria, including pathogenesisassociated mechanisms. The discovery of 39 novel genes in C. glutamicum $\mathrm{R}$ that have not been previously reported in other corynebacteria supports the rationale for sequencing additional corynebacterial genomes to better define the corynebacterial pan-genome and identify previously undetected metabolic pathways in these organisms.
\end{abstract}

\section{INTRODUCTION}

Corynebacterium glutamicum is a fast-growing, aerobic, non-sporulating, non-motile, saprophytic, Gram-positive micro-organism that can be isolated from soil samples based on its properties to secrete large amounts of glutamic acid under suitable conditions (Kumagai, 2000; Vertès et al., 2005). Corynebacteria belong to the order Actinomycetales of the eubacteria that is characterized by a high $\mathrm{G}+\mathrm{C}$ content and that constitutes a different evolutionary line from that formed by low- $\mathrm{G}+\mathrm{C}$ content micro-organisms such as bacilli or clostridia (Stackebrandt \& Woese, 1981; Stackebrandt et al., 1997). The genus Corynebacterium is closely related to Mycobacterium and Nocardia, among other

tPresent address: Institute of Plant Biology, Hungarian Academy of Sciences, Szeged, Hungary.

Abbreviations: CDS, coding sequence(s); COG, clusters of orthologous groups; ECF, extracytoplasmic function; PTS, phosphotransferase system; SSI, strain-specific island.

The DDBJ/EMBL/GenBank accession numbers for the complete sequence of the $C$. glutamicum $R$ genome and its native episome PCgR1 are AP009044 and AP009045, respectively.

Tables of strains and plasmids, and of oligonucleotides and primers used in this study are available with the online version of this paper. genera, which form the Corynebacterineae suborder (Liebl, 2005). The genus includes both aerobes and facultative anaerobes, is phenotypically very diverse and forms a monophyletic group that exhibits considerable phylogenetic depth (Liebl, 2005). It consists of 59 validly described species, of which two taxon groups and 35 species are medically relevant (von Graevenitz \& Bernard, 2001). Nonmedical corynebacteria are widely disseminated in nature and have been isolated from a number of different environments other than soil, including dairy products, plant material, faeces and animal skin (Liebl, 2001). Except for phage-mediated transfer and a few conjugative plasmids, corynebacteria appear devoid of a natural competence system for exogenous DNA uptake (Vertès et al., 2005). C. glutamicum has a long history of use for the industrial production of various primary metabolites, including amino acids and nucleotides (Demain, 2000; Hermann, 2003). Moreover, its potential as a commodity chemicals producer (Inui et al., 2004) and for bioremediation applications (Shen et al., 2005) is the focus of increasing research efforts.

The complete genome sequences of two variants of $C$. glutamicum ATCC 13032 have been published (Ikeda \& Nakagawa, 2003; Kalinowski et al., 2003), as have those of 
the closely related Corynebacterium efficiens YS-314 (Nishio et al., 2003), and of the two human pathogens Corynebacterium jeikeium K411 (Tauch et al., 2005) and Corynebacterium diphtheriae NCTC 13129 (Cerdeño-Tárraga et al., 2003). We report here the genomic sequence of $C$. glutamicum R, a strain with industrial potential (Inui et al., 2004) that was isolated from soil sampled in Japan.

The availability of these different genomic data allows the identification of the corynebacterial core genes and of those genes directly related to various ecological niches. In addition, comparative analysis of the sigma factors, secreted proteins, sugar metabolism and two-component systems present in C. glutamicum R enables further assessment of the industrial potential of this strain and its metabolic and regulatory specificities.

\section{METHODS}

Plasmids, bacterial strains and culture conditions. Strains and plasmids used in this study are shown in supplementary Table S1 (available with the online version of this paper). C. glutamicum $\mathrm{R}$ is a strain from our laboratory collection that was isolated in Japan from a meadow soil sample. Escherichia coli cells were grown at $37^{\circ} \mathrm{C}$ in LB medium supplemented where necessary with $50 \mu \mathrm{g} \mathrm{ml}^{-1}$ of either ampicillin (Ap) or chloramphenicol (Cm) (Sambrook et al., 1989). Unless otherwise stated, C. glutamicum and C. efficiens cells were grown in nutrient-rich A medium (Inui et al., 2004) at $33^{\circ} \mathrm{C}$ for $48 \mathrm{~h}$. For sugar utilization experiments, a corynebacterial cell starter culture grown aerobically until late exponential phase in A-medium containing $40 \mathrm{~g}$ glucose $1^{-1}$ was used to inoculate BT minimum medium (Inui et al., 2004) containing $40 \mathrm{~g} \mathrm{l}^{-1}$ of the sugar being tested, using glucose as a positive control for growth.

DNA techniques. Corynebacterial chromosomal DNA was isolated following standard methods (Sambrook et al., 1989) modified by using $4 \mathrm{mg}$ lysozyme $\mathrm{ml}^{-1}$ at $37^{\circ} \mathrm{C}$ for $30 \mathrm{~min}$. Cells were transformed as previously described (Vertès et al., 1993b) using E. coli JM110 plasmid DNA. E. coli plasmid DNA isolation and strain transformation were performed following standard methods (Sambrook et al., 1989). Restriction endonucleases, Klenow fragment and T4 DNA ligase were used as per the manufacturer's instructions (Takara). Restriction fragments were isolated from agarose gels with the GeneClean kit (Bio 101), according to the manufacturer's instructions. PCR was performed using Ex-Taq DNA polymerase (Takara). Prior to sequencing, exonuclease treatment was performed using ExoSAP-IT (USB), as per the manufacturer's instructions.

Library construction. Random fragments resulting from sonication of C. glutamicum R chromosomal DNA were separated on agarose gel into one $2-3 \mathrm{~kb}$ pool and another $8-9 \mathrm{~kb}$ pool. The fragments were blunted and ligated into SmaI-digested pUC119. The ligation mixture was used to transform E. coli JM109 and recombinants were selected on IPTG-supplemented plates. Gaps between contigs were closed using a Lambda FIX II/XhoI replacement phage library with a mean insert size of $20 \mathrm{~kb}$, as per the manufacturer's instructions (Stratagene). Fragments (1-2 kb) at the end of the assembled contigs were amplified by PCR from the chromosomal DNA of C. glutamicum R, labelled using a Gene Image Random Prime Labelling Module (GE Healthcare Bio-Sciences Corp.) and used as probes to screen the phage library by plaque hybridization. Several genomic DNA fragments extracted from the positive phage clones were sequenced after subcloning into vector pUC18 (Sambrook et al., 1989). For sequencing purposes, E. coli clones bearing C. glutamicum
R chromosomal DNA fragments were grown overnight and the corresponding plasmids were isolated. Gaps in the assembled sequence were closed by PCR-mediated genome walking.

Genome sequencing. Using the whole-genome shotgun method, libraries of 2-3, 8-9 and $20 \mathrm{~kb}$ genomic inserts were sequenced from both ends using M13 universal forward and reverse primers (Sambrook et al., 1989) and cycle-sequenced using the BigDye Terminator method in ABI $3700 \mathrm{CE}$ and ABI 3730 DNA analysers (Applied Biosystems). The sequences were base-called and assembled using Phred, Phrap and Consed (Ewing et al., 1998; Gordon et al., 1998). The Pregap4 program of the Staden package (Bonfield et al., 1995; Staden, 1996) was used for clipping vector sequences, as well as for quality clipping and contamination screening after base-calling by Phred (Ewing \& Green, 1998; Ewing et al., 1998). Gaps were closed by primer walking on gap-spanning plasmid clones and direct sequencing of PCR products. Repetitive sequences such as rDNA were confirmed by PCR. The error rate was lower than 2 bases per $10 \mathrm{~kb}$ as calculated using Consed (Gordon et al., 1998).

Gene prediction and analysis. rRNAs were located by a BLASTN homology search against the 16S, 23S and 5S rRNA sequences of $C$. glutamicum ATCC 13032. tRNAs were predicted by tRNA scan SE (Lowe \& Eddy, 1997). Protein coding sequences (CDS) were predicted using Glimmer3 (Delcher et al., 1999a; Salzberg et al., 1998) and GeneMarkS (Besemer et al., 2001). Proteome prediction was performed by a BLASTP homology search using an e-value lower than $1 \times \mathrm{e}^{-4}$ against GenBank release 152, GenPept release 152, UniProt release 4.6, the NCBI clusters of orthologous groups (COG) database (Tatusov et al., 1997) and the Pfam family database (Accelrys GCG Wisconsin package version 11.0). Numerous annotations were checked manually after the auto-annotations were performed. The search for repeats at each extremity of each of the 10 major strainspecific islands (SSIs) present in the genome of C. glutamicum $\mathrm{R}$ (Suzuki et al., 2005a) was performed using the EMBOss package (Rice et al., 2000).

Identification of orthologous CDS and genomic islands. All the CDS of C. glutamicum R, C. glutamicum ATCC 13032 (Ikeda \& Nakagawa, 2003; Kalinowski et al., 2003), C. efficiens YS-314 (Nishio et al., 2003), C. diphtheriae NCTC 13129 (Cerdeño-Tárraga et al., 2003) and C. jeikeium K411 (Tauch et al., 2005) were compared to each other in a reciprocal manner using BLASTP with an e-value of $\times \mathrm{e}^{-4}$ as a cut-off. Genes showing the highest similarity levels in a dual strain comparison were automatically parsed for every CDS present in both strains using an original Perl script. The CDS with a reciprocal best hit were defined as being orthologous CDS of the two strains.

Identification of genomic DNA islands in the C. glutamicum $\mathrm{R}$ and $C$. glutamicum ATCC 13032 genome was performed using MUMer2.1 (Delcher et al., 1999b, 2002).

Transposon, deletion, and gene disruption and replacement mutagenesis. We used a combination of Tn5 and Tn 31831 mutagenesis systems to assemble a library of 2300 different transposon mutants (Suzuki et al., 2006; Vertès et al., 2005), and the Cre-loxP system (Suzuki et al., 2005b) to generate deletion mutants. Mutations were verified by PCR using the oligonucleotides and nucleotide primers shown in Supplementary Table S2 (available with the online version of this paper). Gene disruption and replacement mutagenesis were performed as described previously (Vertès et al., 1993a) using primers indicated in Supplementary Table S2.

Gene identification numbers. Gene identification numbers are from the Virtual Institute of Microbial Stress and Survival (VIMSS) database (Alm et al., 2005). 


\section{RESULTS AND DISCUSSION}

\section{General features of C. glutamicum $\mathbf{R}$}

The genetic basis of C. glutamicum R consists of a $49120 \mathrm{bp}$ native episome (PCgR1) and one circular chromosome of 3314179 bp encoding 2990 ORFs with a mean length of 957 bp (Table 1 and Fig. 1). The $\mathrm{G}+\mathrm{C}$ content of the chromosome is $54.1 \mathrm{~mol} \%$ overall, $55.2 \mathrm{~mol} \%$ for the protein coding regions and $47.4 \mathrm{~mol} \%$ for the non-coding regions. PCgR1 exhibits a $\mathrm{G}+\mathrm{C}$ content of $53.9 \mathrm{~mol} \%$ that is very similar to that of the chromosome, suggesting that its acquisition by strain $\mathrm{R}$ is not a recent event unless it was acquired by horizontal transfer from an organism with similar $\mathrm{G}+\mathrm{C}$ content. It encodes 28 putative proteins, $647 \mathrm{bp}$ long on average, and has a relatively low coding density $(36.9 \%)$. It does not appear to be similar to any episome previously identified in corynebacteria. The G+C content of the protein coding regions of PCgR1 is $55.4 \mathrm{~mol} \%$ on average and that of the non-coding regions, $53.1 \mathrm{~mol} \%$.

The size of the C. glutamicum R genome is similar to that of the other saprophytic corynebacteria that have been sequenced to date, and significantly larger than that of the genomes of the pathogenic organisms $C$. jeikeium and $C$. diphtheriae (Table 1). The lower number of genes observed in the clinical isolates sequenced to date perhaps reflects that fewer metabolic functions are needed for corynebacteria to occupy a clinical ecological niche rather than a soil-based environment, consistent with the observation that gene decay and gene reduction have played a central role in the evolution of the Mycobacterium leprae (Cole et al., 2001) and C. diphtheriae (Nishio et al., 2004) chromosomes. These various corynebacterial complete genome sequences confirm the observation that, of the organisms forming the

Table 1. General features of C. glutamicum $\mathrm{R}$ and related bacteria

Abbreviations: Cg R, C. glutamicum R; Cg K, Kitasato University C. glutamicum ATCC 13032 isolate; Cg B, Bielefeld University C. glutamicum ATCC 13032 isolate; Ce, C. efficiens; Cj, C. jeikeium; Ms, Mycobacterium smegmatis; Mt, Mycobacterium tuberculosis; Nf, Nocardia farcinica. The M. smegmatis sequence was obtained from The Institute of Genome Research (TIGR).

\begin{tabular}{|c|c|c|c|c|c|c|c|c|c|}
\hline Feature & $C g \mathrm{R}$ & $C g$ K & $C g$ B & $C e$ & $C j$ & $C d$ & Ms & $M t$ & $N f$ \\
\hline Accession no. & AP009044 & NC003450 & BX927147 & BA000035 & CR931997 & BX248353 & & AL123456 & AP006618 \\
\hline Strain & $\mathrm{R}$ & ATCC 13032 & ATCC 13032 & YS-314 & K411 & NCTC 13129 & MC2 & $\mathrm{H} 37 \mathrm{Rv}$ & IFM 10152 \\
\hline Reference & $\begin{array}{l}\text { This } \\
\text { work }\end{array}$ & $\begin{array}{c}\text { Ikeda \& } \\
\text { Nakagawa } \\
(2003)\end{array}$ & $\begin{array}{l}\text { Kalinowski } \\
\text { et al. } \\
(2003)\end{array}$ & $\begin{array}{l}\text { Nishio } \\
\text { et al. } \\
(2003)\end{array}$ & $\begin{array}{l}\text { Tauch } \\
\text { et al. } \\
(2005)\end{array}$ & $\begin{array}{l}\text { Cerdeño-Tárraga } \\
\text { et al. (2003) }\end{array}$ & TIGR & $\begin{array}{l}\text { Cole et al. } \\
(1998,2001)\end{array}$ & $\begin{array}{l}\text { Ishikawa } \\
\text { et al. } \\
(2004)\end{array}$ \\
\hline $\begin{array}{l}\text { Total genome } \\
\text { size (bp) }\end{array}$ & 3314179 & 3309401 & 3282708 & 3147090 & 2462499 & 2488635 & 6988209 & 4411532 & 6021225 \\
\hline $\begin{array}{l}\text { Genome } \mathrm{G}+\mathrm{C} \\
\text { content }(\mathrm{mol} \%)\end{array}$ & 54.10 & 53.80 & 53.80 & 63.40 & 61.40 & 53.50 & 67.40 & 65.60 & 70.80 \\
\hline No. of ORFs & 2990 & 2993 & 3002 & 2950 & 2104 & 2320 & 6829 & 3959 & 5674 \\
\hline $\begin{array}{l}\text { Mean ORF } \\
\text { length (bp) }\end{array}$ & 957 & 933 & 916 & 979 & 1030 & 964 & 1005 & 1012 & 960 \\
\hline $\begin{array}{l}\text { Coding density } \\
(\%)\end{array}$ & 86.30 & 86.80 & 88.30 & 90.40 & 89.20 & 89.60 & 99.20 & 90.80 & 90.4 \\
\hline tRNA & 57 & 60 & 60 & 56 & 50 & 54 & 47 & 45 & 53 \\
\hline 16S RNA & 6 & 6 & 6 & 5 & 3 & 5 & 2 & 4 & 3 \\
\hline 23S RNA & 6 & 6 & 6 & 5 & 3 & 5 & 2 & 4 & 3 \\
\hline 5S RNA & 6 & 6 & 6 & 5 & 3 & 5 & 2 & 0 & 3 \\
\hline \multicolumn{10}{|l|}{ Episome 1} \\
\hline Accession no. & AP009045 & & & AP005225 & AF401314 & & & & AP006619 \\
\hline Size (bp) & $\begin{array}{l}\text { PCgR1: } \\
49120\end{array}$ & & & $\begin{array}{l}\text { pCE2: } \\
23743\end{array}$ & $\begin{array}{l}\text { pKW4: } \\
14323\end{array}$ & & & & $\begin{array}{l}\text { pNF1: } \\
184026\end{array}$ \\
\hline $\begin{array}{l}\mathrm{G}+\mathrm{C} \text { content } \\
(\mathrm{mol} \%)\end{array}$ & 53.9 & & & 54.4 & 53.8 & & & & 67.2 \\
\hline \multicolumn{10}{|l|}{ Episome 2} \\
\hline Accession no. & & & & AP005226 & & & & & AP006620 \\
\hline Size (bp) & & & & $\begin{array}{l}\text { pCE3: } \\
48672\end{array}$ & & & & & $\begin{array}{l}\text { pNF2: } \\
87093\end{array}$ \\
\hline $\begin{array}{l}\mathrm{G}+\mathrm{C} \text { content } \\
(\mathrm{mol} \%)\end{array}$ & & & & 56.4 & & & & & 68.4 \\
\hline
\end{tabular}




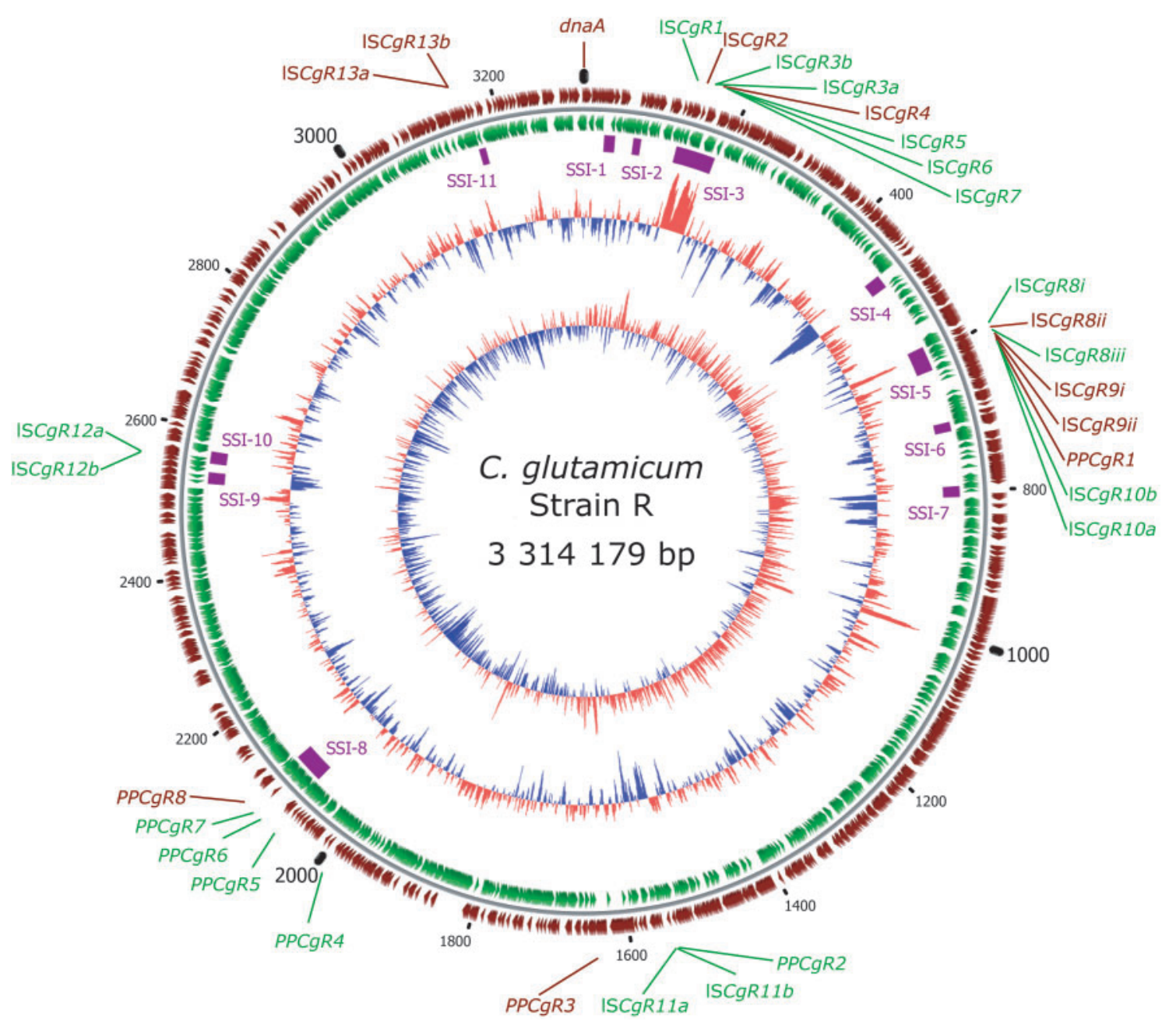

Fig. 1. Circular representation of the genome of C. glutamicum R. The first base of the initiation codon of the $d n a A$ gene was set as the origin of the coordinates. Coordinates are given in $\mathrm{kb}$. The two outermost circles represent the predicted CDS on the forward (maroon) strand on the outside and reverse (green) strand on the inside. The third circle from the outside shows the location of SSIs greater than $10 \mathrm{~kb}$ (SSI-1-SSI-11) along the genome. The localization of insertion sequences (ISCgR1ISCgR13) and phage-derived proteins (PPCgR1-PPCgR8) is depicted. The colour of the labelled genes corresponds to the colour of the strand on which they are located. The fourth and fifth circles represent the $\mathrm{G}+\mathrm{C}$ content and the $\mathrm{GC}$ skew (G$C) /(G+C)$, respectively, each plotted using a $3000 \mathrm{bp}$ window with a $1000 \mathrm{bp}$ window overlap. Red regions (pointing outwards) in these two circles are those of high $\mathrm{G}+\mathrm{C}$ content or high $\mathrm{GC}$ skew, whereas blue regions (pointing inwards) are those of low $\mathrm{G}+\mathrm{C}$ content or low $\mathrm{GC}$ skew. The map was created using original scripts and the CGView software (Stothard $\&$ Wishart, 2005).

Corynebacterineae phylogenetic cluster, corynebacteria have both the smallest genomes and the lowest coding densities (Table 1), although this difference is perhaps an artifact as gene finding in genomes of high $\mathrm{G}+\mathrm{C}$ content tends to predict more or extended coding regions due to lower frequencies of stop codons.

The genome of strain $\mathrm{R}$ encodes 6 rRNA operons and 57 tRNA genes. The first base of the initiation codon of the $d n a A$ gene was designated as the sequence coordinate origin. It is located near characteristic replication regions. The GC skew analysis (Grigoriev, 1998) presented in Fig. 1 supports the view that DNA replication in C. glutamicum is bidirectional, as observed in strain ATCC 13032 (Kalinowski et al., 2003). It is noteworthy that the $\mathrm{G}+\mathrm{C}$ content variation is low in this genome. Nevertheless, a comparison of the genome of C. glutamicum strain $\mathrm{R}$ with the published genome sequences of two isolates of C. glutamicum ATCC 13032 (Ikeda \& Nakagawa, 2003; Kalinowski et al., 2003) revealed the presence of hundreds of SSIs (Suzuki et al., 2005b). In particular, strain $\mathrm{R}$ exhibits 11 SSIs larger than $10 \mathrm{~kb}$ (Fig. 1) that have a G $+\mathrm{C}$ content ranging from 45.7 to $60.7 \mathrm{~mol} \%$ (Suzuki et al., 2005a). Notably, none of these was observed to be flanked by obvious repeats. However, it is 
noteworthy that strain R is devoid of the AT-rich $211 \mathrm{~kb}$ genomic island with clear boundaries (Zhang \& Zhang, 2004) that is carried by strain ATCC 13032 and that contains genes typically associated with horizontal transfer, such as a restriction-modification system, transposases, recombination enzymes and phage-derived sequences (Kalinowski et al., 2003). Likewise, the AT-rich $25 \mathrm{~kb}$ region harboured by strain ATCC 13032 containing the genes cg0414-cg0440 is absent from the strain $\mathrm{R}$ genome. It is noteworthy that products of these genes are involved in cell wall formation, including cell surface polysaccharide ( $w z z, \operatorname{cg} 0414)$, lipopolysaccharide (various glycosyl transferases) or murein formation (murA, $\operatorname{cg} 0422$; murB, $\operatorname{cg} 0423$ ). These observations suggest that measurable differences could exist between the cell walls of the two strains that could perhaps form the basis of immunotyping procedures. Furthermore, the $14 \mathrm{~kb} \mathrm{G}+\mathrm{C}$ rich region identified in the genome of strain ATCC 13032 (Kalinowski et al., 2003) to contain C. diphtheriae sequences ( $95 \%$ identity at the nucleotide level) is absent from the genome of strain $\mathrm{R}$, which does not exhibit any sequence similar to the gene cluster cg3276-cg3290. This observation promotes the view that these genes have, on an evolutionary timescale, recently been acquired by C. glutamicum ATCC 13032 in a horizontal transfer event originating from $C$. diphtheriae. On the other hand, it is noteworthy that the strain R SSI-4, characterized by a low G + C content ( $45.7 \mathrm{~mol} \%$ ) (Suzuki et al., 2005a), and thus probably resulting from a horizontal transfer, does not contain any obvious phage- or mobile-element-related sequence.

Strain $\mathrm{R}$ encodes 22 sequences homologous to mobile elements, including six incomplete insertion sequence signatures, and five insertion sequences that contain two ORFs which putatively form a full transposase protein via a frameshift (ISCgR3a-b, ISCgR10a-b, ISCgR11a-b, ISCgR12a-b, ISCgR13a-b) (Table 2). The presumably functional mobile elements found in C. glutamicum $\mathrm{R}$ originate from two different families (IS3, ISCgR11; IS6, ISCgR1, ISCgR2, ISCgR9), as defined by Mahillon \& Chandler (1998). ISCgR9 is an isoform of IS1628 (Mahillon \& Chandler, 1998). ISCgR3 and ISCgR13 constitute novel elements that share a relatively low level of identity at the amino acid level with a putative Rhodococcus erythropolis insertion sequence (Stecker et al., 2003). Similar to what is observed in strain ATCC 13032, SSIs in strain R are rich in mobile elements, particularly SSI-3 ( $\mathrm{G}+\mathrm{C}$ content, $60.7 \mathrm{~mol} \%$ ) and SSI-5 (55.2 mol\%) (Table 2). On the other hand, fewer genes of phage origin are present in the genome of C. glutamicum $\mathrm{R}$ as compared to C. glutamicum ATCC 13032 since only phage remnants are observed (Table 2). Nevertheless, SSI-8, $42.7 \mathrm{~kb}$ in size and with a $\mathrm{G}+\mathrm{C}$ content of $52.1 \mathrm{~mol} \%$ (Suzuki et al., 2005a), could have originated from a previously unknown phage as it encodes numerous hypothetical proteins and several ORFs, the products of which share some homology to known phage proteins. This is in sharp contrast to what is observed in C. glutamicum ATCC 13032 isolates that harbour three to four different putative prophages (Kalinowski, 2005).

\section{Chromosome structure}

As previously observed (Kalinowski et al., 2003; Nakamura et al., 2003), corynebacterial genomes, including that of strain $\mathrm{R}$, show a very high degree of synteny with a striking lack of detectable inversions (not shown). The C. jeikeium genome, however, exhibits 10 apparent breakpoints of synteny with C. glutamicum ATCC 13032 (Tauch et al., 2005). Likewise, the genomes of the relatively closely related mycobacteria show that extensive rearrangements have occurred in these species throughout the course of evolution. This phenomenon has been ascribed to the lack of a complete RecBCD recombination repair system in corynebacteria (Nakamura et al., 2003), despite the presence of $r e c A$ and $r e c B$ genes. Nevertheless, as demonstrated by the rearrangements that have occurred in the genome of $C$. jeikeium, other recombination mechanisms may be at play that allow moderate reorganizations in the chromosome architecture.

The C. glutamicum R and ATCC 13032 genomes contain similar numbers of putative operons in concordance with the numbers of rho-independent transcription terminators containing a stem-loop and poly-U tail. Using the TIGR Comprehensive Microbial Resource (Ermolaeva et al., 2001), we calculated that C. glutamicum ATCC 13032 contains 455 operons and 485 rho-independent terminators. Notably, $c g R 1278$, encoding the transcription termination factor rho, is probably an essential gene in $C$. glutamicum R (Suzuki et al., 2006).

\section{Corynebacterial core genes}

The corynebacterial backbone, defined by the set of orthologous genes present in all corynebacteria sequenced to date [C. glutamicum ATCC 13032 (Ikeda \& Nakagawa, 2003; Kalinowski et al., 2003), C. glutamicum R (this work), C. efficiens YS-314 (Nishio et al., 2003), C. jeikeium K411 (Tauch et al., 2005) and C. diphtheriae NCTC 13129 (Cerdeño-Tárraga et al., 2003)], comprises 835 genes assigned to COG categories (Table 3), with the total number of shared genes corresponding to approximately a third of the genes present in the saprophytic corynebacteria, in agreement with the value reported by other authors (Tauch et al., 2005) (1089 genes). However, the subset of genes that are essential is significantly lower than the core corynebacterial genome, as demonstrated by the successful transposon mutagenesis of at least $75 \%$ of the ORFs of strain R using transposons Tn5 and Tn31831 (Suzuki et al., 2006; Vertès et al., 2005). It has been demonstrated that the genes that are indispensable for growth of Bacillus subtilis cells in rich medium under standard laboratory conditions belong to the following known categories: DNA and RNA metabolism, protein synthesis, cell envelope, cell shape and division, glycolysis, respiratory pathways, nucleotides and cofactors (Kobayashi et al., 2003). Based on the genomic sequences of C. glutamicum R (this work) and of other corynebacteria (Cerdeño-Tárraga et al., 2003; Ikeda \& Nakagawa, 2003; Kalinowski et al., 2003; Nishio et al., 2003; 
Table 2. Insertion sequences and phage-derived sequences in the C. glutamicum $\mathrm{R}$ genome

The sizes of ORFs are given in bp. The direction of transcription is given relative to the dnaA gene (+, clockwise, -, anticlockwise). Identity levels are calculated based on putative amino acid sequences. Homologous genes: IS1673 is from the C. glutamicum plasmid pCG4 (Tauch et al., 2003), IS1870 is from the C. glutamicum pTET3 plasmid (Tauch et al., 2002), PBD2.162 and PBD2.163 are from the Rhodococcus erythropolis linear plasmid pBD2 (Stecker et al., 2003), IS30 is from E. coli K-12 (Blattner et al., 1997), IS6110 is from Mycobacterium avium (Li et al., 2005), IS1628 is from the C. glutamicum plasmid pCG4 (Tauch et al., 2003), IS1206 [isoform ISCg14 (Kalinowski et al., 2003)] is from the C. glutamicum chromosome (Bonamy et al., 1994). Putative tnp, Putative transposase gene; IR, inverted repeats; NF, not found. SSI-3 has a G+C content of $60.7 \mathrm{~mol} \%$; SSI-5, $55.2 \mathrm{~mol} \%$; SSI-8, 52.1 mol\%; and SSI-10, 53.0 mol\% (Suzuki et al., 2005a).

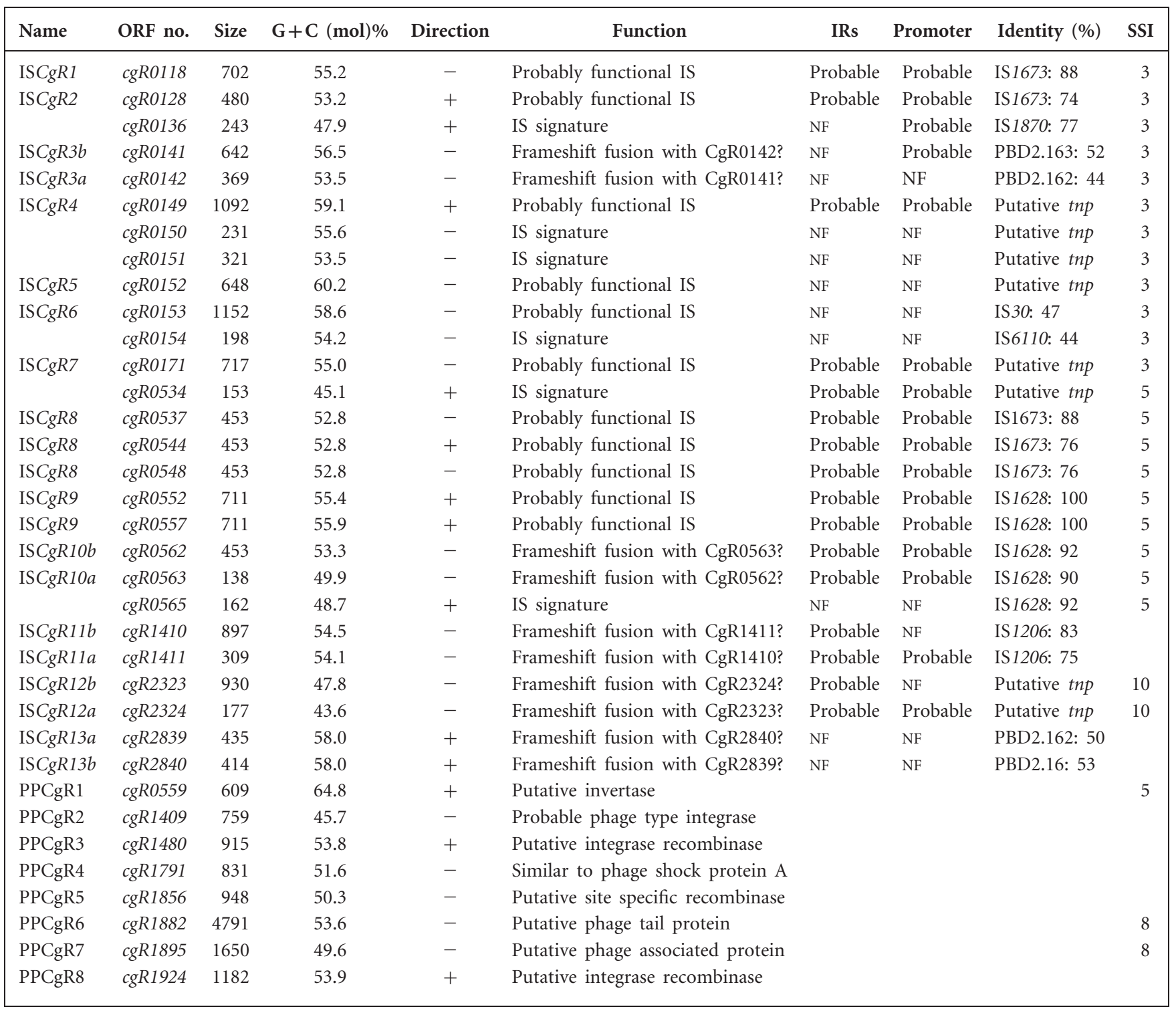

Tauch et al., 2005), these fundamental cellular processes are also essentially conserved in corynebacterial genomes.

\section{Sigma factors}

Ecological niches in soil are characterized by the availability of numerous growth substrates. The pan-genome of saprophytic organisms contains numerous enzymic activities necessary for the breakdown of a large variety of complex molecules. While saprophytic fungi play a predominant role in the recycling of organic matter, numerous enzymes are secreted by bacterial saprophytes to hydrolyse polysaccharides, proteins and lipids. Likewise, saprophytic organisms need to deploy a variety of adaptive responses to cope with various environmental stresses that can range, for a soil bacterium, from nutrient limitation, external osmolality fluctuations and oxygen deprivation to temperature shock. These responses are typically regulated 
Table 3. Classification of C. glutamicum R CDS by COG

ORFs were analysed by BLASTP for each of the genomes of the corynebacteria sequenced to date against the NCBI COG database. Results were parsed for hits with an e-value cutoff of $1 \times \mathrm{e}^{-25}$. Proteins containing multiple functional domains were forced into only one COG category by elimination of duplicates. In accordance with their COG identities, the resultant hits were grouped into the following categories: Cg R, total hits of C. glutamicum R; Core, hits with orthologues in all the corynebacteria sequenced to date; Sap, hits with orthologues only in the saprophytic corynebacteria sequenced to date; Cglut, hits with orthologues only in both C. glutamicum R and the Kitasato University C. glutamicum ATCC 13032 isolate; R spec, non-core, non-C. glutamicum and non-saprophytic hits of strain R; Cg K, C. glutamicum ATCC 13032 Kitasato (Ikeda \& Nakagawa, 2003); K spec, non-core, non-C. glutamicum and non-saprophytic hits of ATCC 13032 Kitasato strain; $C e$, total hits of C. efficiens YS-314; Ce spec, non-core and non-saprophytic hits of C. efficiens; Path, non-core genes present in both of the pathogenic corynebacteria sequenced to date; $C d$, total hits of $C$. diphtheriae NTCT 13129; $C d$ spec, non-core and non-pathogen-specific hits of $C$. diphtheriae; $C$ j, total hits of $C$. jeikeium $\mathrm{K} 411$; $C j$ spec, non-core and non-pathogen-specific hits of $C$. jeikeium. Genes that could not be assigned to a COG category are not included in the Table.

\begin{tabular}{|c|c|c|c|c|c|c|c|c|c|c|c|c|c|c|c|}
\hline NCBI COG & & $\begin{array}{l}\mathrm{Cg} \\
\mathrm{R}\end{array}$ & Core & Sap & Cglut & $\begin{array}{c}\mathrm{R} \\
\text { spec }\end{array}$ & $C g \mathrm{~K}$ & $\begin{array}{c}\text { K } \\
\text { spec }\end{array}$ & $C e$ & $\begin{array}{c}\text { Ce } \\
\text { spec }\end{array}$ & $C d$ & Path & $\begin{array}{c}C d \\
\text { spec }\end{array}$ & $C j$ & $\begin{array}{r}C j \\
\text { spec }\end{array}$ \\
\hline \multicolumn{16}{|c|}{ Information storage and processing } \\
\hline $\mathrm{J}$ & $\begin{array}{l}\text { Translation, ribosomal } \\
\text { structure and biogenesis }\end{array}$ & 139 & 117 & 13 & 6 & 3 & 140 & 4 & 135 & 5 & 131 & 3 & 11 & 129 & 9 \\
\hline A & RNA processing and modification & 1 & 1 & 0 & 0 & 0 & 1 & 0 & 1 & 0 & 1 & 0 & 0 & 1 & 0 \\
\hline K & Transcription & 145 & 42 & 58 & 35 & 10 & 143 & 8 & 107 & 7 & 69 & 1 & 26 & 55 & 12 \\
\hline $\mathrm{L}$ & $\begin{array}{l}\text { Replication, recombination } \\
\text { and repair }\end{array}$ & 96 & 53 & 24 & 9 & 10 & 113 & 27 & 102 & 25 & 79 & 9 & 17 & 77 & 15 \\
\hline \multicolumn{16}{|c|}{ Cellular processes and signalling } \\
\hline $\mathrm{D}$ & $\begin{array}{l}\text { Cell cycle control, cell division, } \\
\text { chromosome partitioning }\end{array}$ & 17 & 13 & 2 & 2 & 0 & 18 & 1 & 16 & 1 & 17 & 1 & 3 & 22 & 8 \\
\hline V & Defence mechanisms & 42 & 12 & 13 & 15 & 2 & 43 & 3 & 39 & 14 & 35 & 4 & 19 & 43 & 14 \\
\hline $\mathrm{T}$ & Signal transduction mechanisms & 37 & 18 & 13 & 5 & 1 & 40 & 4 & 34 & 3 & 22 & 1 & 3 & 25 & 6 \\
\hline M & $\begin{array}{l}\text { Cell wall/membrane/envelope } \\
\text { biogenesis }\end{array}$ & 84 & 49 & 16 & 8 & 11 & 89 & 16 & 81 & 16 & 71 & 3 & 20 & 65 & 13 \\
\hline $\mathrm{U}$ & $\begin{array}{l}\text { Intracellular trafficking, secretion } \\
\text { and vesicular transport }\end{array}$ & 16 & 11 & 3 & 1 & 1 & 16 & 1 & 15 & 1 & 15 & 1 & 3 & 12 & 0 \\
\hline $\mathrm{O}$ & $\begin{array}{l}\text { Post-translational modification, } \\
\text { protein turnover, chaperones }\end{array}$ & 67 & 35 & 21 & 9 & 2 & 71 & 6 & 61 & 5 & 56 & 5 & 16 & 45 & 5 \\
\hline \multicolumn{16}{|l|}{ Metabolism } \\
\hline C & Energy production and conversion & 117 & 42 & 44 & 20 & 11 & 113 & 7 & 99 & 13 & 78 & 3 & 33 & 68 & 23 \\
\hline G & $\begin{array}{l}\text { Carbohydrate transport and } \\
\text { metabolism }\end{array}$ & 136 & 43 & 48 & 27 & 18 & 124 & 6 & 107 & 16 & 83 & 4 & 36 & 64 & 17 \\
\hline E & Amino acid transport and metabolism & 161 & 64 & 67 & 19 & 11 & 160 & 10 & 145 & 14 & 123 & 9 & 50 & 112 & 39 \\
\hline $\mathrm{F}$ & Nucleotide transport and metabolism & 60 & 35 & 20 & 4 & 1 & 62 & 3 & 58 & 3 & 55 & 4 & 16 & 51 & 12 \\
\hline $\mathrm{H}$ & Coenzyme transport and metabolism & 95 & 45 & 40 & 6 & 3 & 95 & 4 & 95 & 10 & 92 & 8 & 39 & 66 & 13 \\
\hline I & Lipid transport and metabolism & 59 & 22 & 18 & 7 & 12 & 58 & 11 & 63 & 23 & 42 & 5 & 15 & 56 & 29 \\
\hline $\mathrm{P}$ & $\begin{array}{l}\text { Inorganic ion transport and } \\
\text { metabolism }\end{array}$ & 159 & 23 & 75 & 43 & 18 & 147 & 6 & 109 & 11 & 70 & 16 & 31 & 81 & 42 \\
\hline Q & $\begin{array}{l}\text { Secondary metabolites biosynthesis, } \\
\text { transport and catabolism }\end{array}$ & 28 & 3 & 16 & 5 & 4 & 26 & 2 & 25 & 6 & 10 & 2 & 5 & 14 & 9 \\
\hline \multicolumn{16}{|c|}{ Poorly characterized } \\
\hline $\mathrm{R}$ & General function prediction only & 223 & 80 & 100 & 38 & 5 & 238 & 20 & 200 & 20 & 133 & 6 & 47 & 123 & 37 \\
\hline S & Function unknown & 165 & 48 & 70 & 33 & 14 & 176 & 25 & 139 & 21 & 104 & 5 & 51 & 76 & 23 \\
\hline Other & & 251 & 79 & 101 & 48 & 23 & 253 & 25 & 214 & 34 & 150 & 10 & 61 & 141 & 52 \\
\hline Total & & 2098 & 835 & 762 & 340 & 160 & 2126 & 189 & 1845 & 248 & 1436 & 100 & 502 & 1326 & 378 \\
\hline
\end{tabular}

via specialized sigma factors of the extracytoplasmic function (ECF) subfamily (Missiakas \& Raina, 1998). The saprophytic organisms Mycobacterium smegmatis (Waagmeester et al., 2005) and Streptomyces avermitilis (Ikeda et al.,
2003) exhibit 26 and 60 putative sigma factors, respectively. In the case of $S$. avermitilis, which belongs to a different suborder of the Actinomycetales from M. smegmatis and $C$. glutamicum, 47 of these belong to the ECF subfamily. On the 
Table 4. Putative sigma factors of corynebacteria

Putative sigma factors were identified by BLASTP searches against the GenBank and VIMSS databases. Gene numbers for $C g$ K, $C e$, $C d$ and Cj refer to the VIMSS database (Alm et al., 2005). Cg R, C. glutamicum strain R; Cg K, C. glutamicum ATCC 13032 Kitasato (Ikeda \& Nakagawa, 2003); Ce, C. efficiens YS-314 (Nishio et al., 2003); Cd, C. diphtheriae NCTC 13129 (Cerdeño-Tárraga et al., 2003); Cj, C. jeikeium K411 (Tauch et al., 2005). Percentage identity scores (Id) were measured against the corresponding C. glutamicum R genes. The designation of the sigma factors is consistent with that used for M. tuberculosis (Waagmeester et al., 2005). The genes listed as pvdS1 and pvdS2 are conserved hypothetical proteins that show a limited homology to sigma factors. In C. glutamicum $\mathrm{R}$, the gene encoding $\sigma^{\mathrm{D}}$ is interrupted by a spacer region. Sizes of genes refer to the number of base pairs.

\begin{tabular}{|c|c|c|c|c|c|c|c|c|c|c|c|c|c|c|}
\hline Gene & $C g \mathrm{R}$ & Size & $C g \mathrm{~K}$ & Size & Id & $\mathrm{Ce}$ & Size & Id & $C d$ & Size & Id & $C j$ & Size & Id \\
\hline $\operatorname{sig} D$ (front) & $\operatorname{cgR} 0718$ & 61 & 374631 & 188 & 90 & 299494 & 190 & 65 & 520259 & 188 & 59 & 844664 & 189 & 38 \\
\hline $\operatorname{sigH}$ & $\operatorname{cgR0876}$ & 207 & 374789 & 206 & 100 & 299671 & 250 & 88 & 520390 & 207 & 77 & 844558 & 209 & 73 \\
\hline$p v d S 1$ & $\operatorname{cgR} 1018$ & 321 & 374936 & 320 & 98 & 299868 & 351 & 76 & 520561 & 301 & 85 & 844437 & 326 & 78 \\
\hline $\operatorname{sig} E$ & $\operatorname{cgR} 1204$ & 214 & 375131 & 213 & 100 & 300066 & 216 & 86 & 520673 & 239 & 83 & 844311 & 196 & 74 \\
\hline $\operatorname{sig} B$ & $\operatorname{cgR} 1749$ & 329 & 375900 & 331 & 99 & 300700 & 333 & 93 & 521103 & 329 & 90 & 844012 & 343 & 85 \\
\hline$p v d S 2$ & $\operatorname{cgR} 2616$ & 307 & 376676 & 306 & 98 & 301447 & 315 & 94 & 521713 & 298 & 89 & 843139 & 296 & 84 \\
\hline $\operatorname{sigM}$ & $\operatorname{cgR} 2979$ & 202 & 377039 & 201 & 100 & 301821 & 251 & 66 & 522059 & 200 & 40 & 845047 & 205 & 27 \\
\hline $\operatorname{sigK}$ & & & & & & & & & 519777 & 194 & & 842888 & 198 & \\
\hline $\operatorname{sigL}$ & & & & & & & & & 520559 & 179 & & & & \\
\hline
\end{tabular}

other hand, C. glutamicum $\mathrm{R}$ harbours fewer of these components of the RNA polymerase complex. As shown in Table 4 , in addition to $\sigma^{\mathrm{A}}$, the sigma factor that directs the transcription of most genes in growing cells, and $\sigma^{\mathrm{B}}$, which plays a crucial role in the maintenance of the stationary phase in M. smegmatis (Mukherjee \& Chatterji, 2005), corynebacteria possess five alternative sigma factors to regulate genetic expression in response to extracellular changes. C. glutamicum R and C. glutamicum ATCC 13032 exhibit the same number of these ECF sigma factors to regulate extracytoplasmic functions, with the exception of $\sigma^{\mathrm{D}}$ which is disrupted by a spacer region in C. glutamicum $\mathrm{R}$. In M. tuberculosis $\mathrm{H} 37 \mathrm{Rv}, \sigma^{\mathrm{D}}$ has been shown to control the expression of ribosome-associated gene products in the stationary phase and to be required for full virulence (Calamita et al., 2005). Similarly, $\sigma^{\mathrm{H}}$ has been observed to regulate major components of oxidative and heat stress responses (Raman et al., 2001), and $\sigma^{\mathrm{L}}$, an orthologue of which is present in C. diphtheriae NCTC 13129 but not in the other corynebacteria sequenced to date, has been observed to regulate polyketide synthases and secreted or membrane proteins (Hahn et al., 2005). In C. jeikeium K411 and C. diphtheriae NCTC 13129, sigH is located upstream of $r s h A$, a putative anti- $\sigma^{\mathrm{H}}$ factor, with which it forms a putative operon, as observed in Nocardia farcinica IFM 10152 (Ishikawa et al., 2004). All corynebacteria sequenced to date contain a $\operatorname{sig} C$ and a $\operatorname{sig} E$ gene. Interestingly, $\sigma^{\mathrm{C}}$ has been shown to be required for lethality of $M$. tuberculosis in mice (Sun et al., 2004), and $\sigma^{\mathrm{E}}$ is induced upon treatment of
M. tuberculosis cells with hydrogen peroxide or upon macrophage infection (Jensen-Cain \& Quinn, 2001). In contrast to what is observed in mycobacteria, where the saprophytic $M$. smegmatis harbours twice as many sigma factors (26 sigma factors) as its pathogenic relative M. tuberculosis (13) (Waagmeester et al., 2005), no sigma factor specific to saprophytic corynebacteria could be identified by homology searches, despite the presence of pathogenic-specific sigma factors in C. diphtheriae NCTC $13129\left(\sigma^{\mathrm{K}}, \sigma^{\mathrm{L}}\right)$ and C. jeikeium $\mathrm{K} 411\left(\sigma^{\mathrm{K}}, \sigma^{\mathrm{L}}, \sigma^{\mathrm{W}}\right)$. This latter observation particularly reinforces the view that $\sigma^{\mathrm{K}}$ is involved in bacterial virulence, as a $\sigma^{\mathrm{K}}$ orthologue is present in $M$. tuberculosis $\mathrm{H} 37 \mathrm{Rv}$ but absent from M. smegmatis MC2 (Waagmeester et al., 2005). Consistent with these predicted functions, we could isolate C. glutamicum R cells mutated by transposon insertion in any of the genes sigH, sigE, sigB, sigM, or $p v d S 1$ and $p v d S 2$ (these latter genes encode two conserved hypothetical proteins that show limited homology with sigma factors, though they are unlikely to encode sigma factors), but not in sigC or sigA. Notably, sigH and sigE are also dispensable in C. glutamicum ATCC 13032 (Engels et al., 2004).

\section{Secreted proteins}

The relative paucity of sigma factor-mediated adaptive mechanisms in corynebacteria reflects the exacting nutrient requirements typically exhibited by these organisms and their relative limitation in extracellular enzymes to digest 
complex molecules present in their environments. Corynebacteria excrete a limited number of proteins, as demonstrated by the identification of only approximately 40 protein spots in the 4.0 to $5.0 \mathrm{pI}$ range during proteome analysis experiments of supernatants of late-exponential growth phase cultures (Hermann et al., 2001), and by the identification of 49 cell-surface protein spots and 89 extracellular protein spots in the 3 to $7 \mathrm{pI}$ range from proteome fractions of C. efficiens YS-314 (Hansmeier et al., 2006). In particular, it has long been known that $C$. glutamicum cell extracts and supernatants do not have broad-spectrum proteolytic activity, as they show only limited extracellular protease activity on skim milk plates. Likewise, these bacteria exhibit limited extracellular lipolytic and nuclease activity, and no cellulase or amylase activity (Yukawa et al, 2007). The large number of transporters found in these bacteria to ensure the uptake of amino acids and peptides (Winnen et al., 2005) can perhaps be ascribed to the limited capability of these organisms to breakdown complex molecules. Nevertheless, mining of the C. glutamicum $\mathrm{R}$ genome reveals the presence of gene $\operatorname{cgR} 1176$ which encodes a putative secreted protease which is $29.6 \%$ identical to the B. subtilis epr gene, the product of which is an extracellular serine protease. Based on in silico homology searches, orthologues of $c g R 1176$ appear to be common in members of the Actinobacteria group. Similarly, $c g R 1002$, a probable pullulanase gene, which is part of a putative three-gene operon in C. glutamicum $\mathrm{R}$, can also be observed in the genome of C. glutamicum ATCC 13032 (VIMSS374909) and in C. efficiens YS-314 as part of a putative four-gene operon, but not in $C$. diphtheriae NCTC 13129 nor C. jeikeium K411. Interestingly, this operon also encodes two hypothetical membrane proteins which are conserved in both saprophytic and pathogenic corynebacteria $(\operatorname{cgR} 1000, \operatorname{cgR} 1001)$. In C. efficiens, this operon is predicted (VIMSS database) to be controlled by CE2422, a transcription regulator of the GntR family of proteins. Homologues of CE2422 are present in both C. glutamicum R ( $c g R 2434)$ and ATCC 13032 (VIMSS376496), and in various Streptomyces species, but not in the pathogenic corynebacteria sequenced to date nor in mycobacteria.

\section{Sugar metabolism}

Corynebacteria are able to utilize only a limited array of different sugars. For example, wild-type C. glutamicum $\mathrm{R}$ cells are able to utilize fructose, glucose, glucuronic acid, glucosamine, maltose, mannose, $\alpha$-methylglucoside, ribose, sucrose, trehalose, arbutin and salicin as sole carbon sources, but not arabinose, galactose, lactose, cellobiose, mannitol, rhamnose, xylose or xylitol (this work). C. glutamicum transports several sugars, including sucrose, fructose and glucose, by the phosphotransferase system (PTS) (Moon et al., 2005; Saier, 2002). Sugar transport plays an important role in the observed substrate range limitation of $C$. glutamicum, as exemplified by the isolation of a spontaneous PTS mutant of C. glutamicum R that is able to extend the catabolic capabilities of this organism to the degradation of cellobiose (Kotrba et al., 2003). However, this limitation in carbon substrate spectrum is also due to the lack of specific catabolic genes, such as the lack of xylose isomerase which prevents the catabolism of the pentose xylose, despite the presence of ATP-binding cassette proteins putatively involved in the transport of this sugar (specifically that encoded by $c g R 1331$, which is part of a five-gene operon containing a lacI-type transcriptional regulator, and which shows, respectively, 48 and $44 \%$ homology to the $x y l F$ genes of Geobacillus kaustophilus HTA426 and E. coli K-12 which encode the periplasmic xylose-binding subunit of a highaffinity xylose $\mathrm{ABC}$-transporter; moreover, synteny comparisons suggest the presence also of the $x y l G(c g R 1329)$ and $x y l H$ genes (cgR1330) encoding, respectively, the ATPbinding and membrane components of a xylose $\mathrm{ABC}$ transporter). In addition, several sugar/proton symports could also be involved in the uptake of xylose by wild-type $C$. glutamicum cells, since cgR0261, cgR2943, cgR2864, cgR2290 and $\operatorname{cgR} 2267$ all show homology levels greater than $40 \%$ with E. coli $x y l E$, a gene that encodes a D-xylose/proton symporter from the major facilitator superfamily of transporters.

Notably, all corynebacteria sequenced to date, including $C$. glutamicum R (cgR1200) and ATCC 13032 (VIMSS376610), as well as C. diphtheriae NCTC 13129 (VIMSS520668) and C. jeikeium K411 (VIMSS844316), exhibit a putative $\beta$ fructofuranosidase gene encoding a protein that is $49 \%$ similar (34\% identical) to the fruA gene product of Bacillus megaterium ATCC 14581 (Chiou et al., 2002). The capacity of corynebacteria to synthesize fructans, and particularly pathogenic corynebacteria, would thus be interesting to verify since fructans can trigger inflammatory reactions (Shilo \& Wolman, 1958) and thus contribute to disease progression. However, only C. glutamicum R (cgR2548) and C. glutamicum ATCC 13032 (VIMSS376610) exhibit a putative sacA gene encoding a second $\beta$-fructofuranosidase. The C. glutamicum sacA gene product shares $48 \%$ homology with the B. subtilis 168 SacA (Glaser et al., 1993) and is only $26 \%$ identical to the product of the putative $C$. glutamicum fruA gene. In both C. glutamicum R and ATCC 13032, sacA is part of a putative four-gene operon that includes a phosphotransferase system component (PTS enzyme IIC) (respectively, cgR2547 and VIMSS376609). Both fruA and sacA are dispensable, as demonstrated by the disruption and replacement of these genes in C. glutamicum $\mathrm{R}$ (this work).

Furthermore, consistent with the notion that corynebacteria use glycogen as their major polyglucan reserve, glycogen metabolism genes are highly conserved among these bacteria. In particular, corynebacterial genomes exhibit sequences homologous to a glycosyl transferase (cgR1201) linked in a putative operon to $g l g C$, the gene encoding ADPglucose pyrophosphorylase (strain R, cgR1202; strain ATCC 13032, VIMSS375129). Also observed are a putative twogene operon, $g l g B$, encoding glycosyl transferase (cgR1302cgR1303), and $g \lg X$, encoding a glycogen debranching 
Table 5. Putative two-component systems of corynebacteria

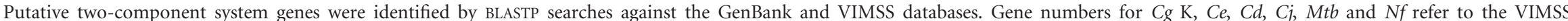

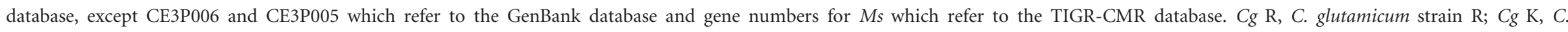

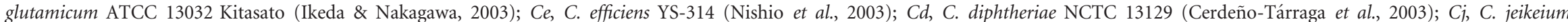

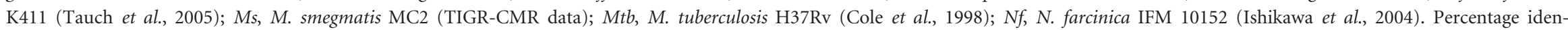

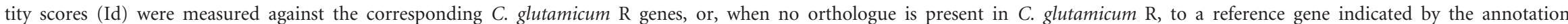

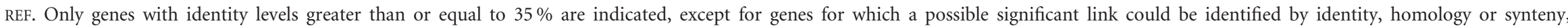

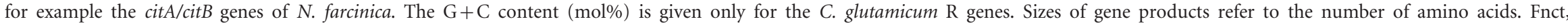

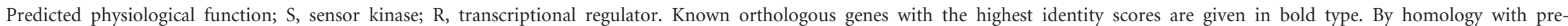

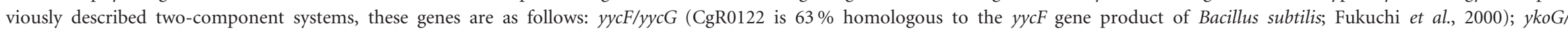

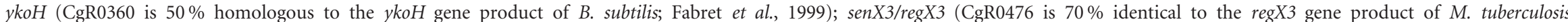

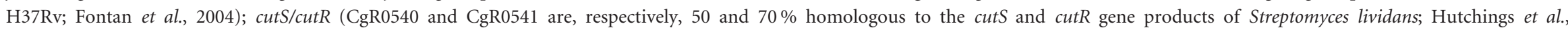

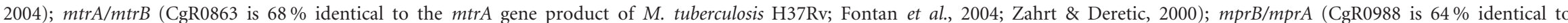

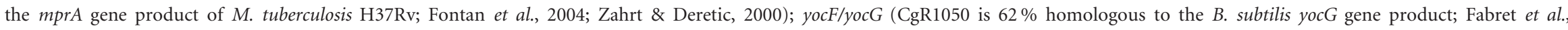

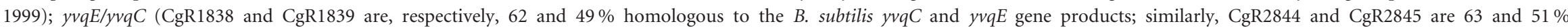

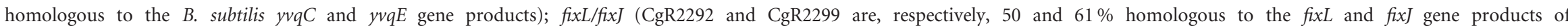

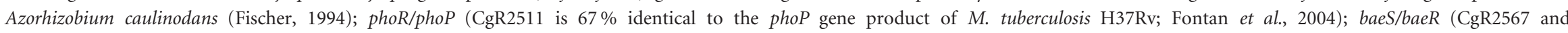

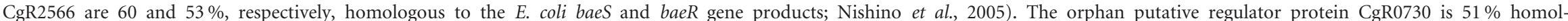

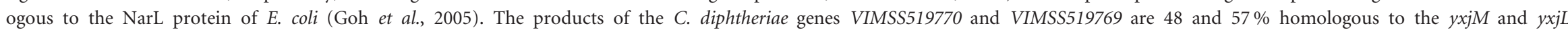

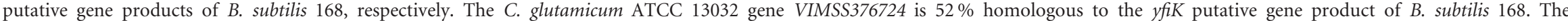

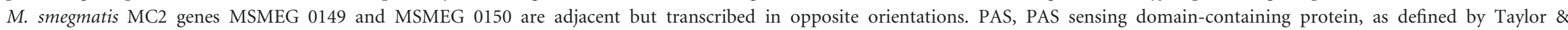
Zhulin (1999).

\begin{tabular}{|c|c|c|c|c|c|c|c|c|c|c|c|c|c|c|c|c|c|c|c|c|c|c|}
\hline Fnct & Gene & $C g \mathrm{R}$ & $\mathrm{G}+\mathrm{C}$ & Size & $C g \mathrm{~K}$ & Size & Id & $C e$ & Size & Id & $C d$ & Size & Id & $C j$ & Size & Id & Ms & Id & $M t b$ & Id & $N f$ & Id \\
\hline S & citA & $\operatorname{cgR} 0088$ & 54 & 564 & 374123 & 551 & 94 & 301794 & 556 & 61 & & & & & & & & & & & 770361 & 28 \\
\hline $\mathrm{R}$ & citB & $\operatorname{cgR} 0089$ & 55 & 218 & 374124 & 218 & 93 & 301793 & 218 & 68 & & & & & & & & & & & 770362 & 31 \\
\hline $\mathrm{R}$ & oxyS & & & & & & & & & & & & & 844678 & 304 & 31 & 0150 & REF & 31888 & 61 & & \\
\hline S & $k d p D$ & & & & & & & & & & & & & 844195 & 898 & REF & 5352 & 44 & 32801 & 39 & 767267 & 41 \\
\hline $\mathrm{R}$ & $k d p E$ & & & & & & & & & & & & & 844196 & 230 & REF & 5376 & 42 & 32800 & 52 & 767268 & 52 \\
\hline S & $y x j M$ & & & & & & & CE3P006 & 425 & 31 & 519770 & 409 & REF & & & & & & & & 776093 & 37 \\
\hline $\mathrm{R}$ & $y x j L$ & & & & & & & CE3P005 & 219 & 46 & 519769 & 219 & REF & & & & & & & & 769975 & 40 \\
\hline $\mathrm{R}$ & $y y c F$ & cgR0122 & 67 & 240 & 376919 & 240 & 91 & 299167 & 240 & 68 & 519745 & 240 & 89 & 844363 & 240 & 90 & & & & & & \\
\hline S & $y y c G$ & $\operatorname{cgR} 0123$ & 65 & 399 & 376918 & 399 & 83 & 299168 & 398 & 57 & 519744 & 375 & 78 & 844362 & 375 & 79 & & & & & & \\
\hline S & PAS & $\operatorname{cgR} 0262$ & 48 & 145 & 374236 & 145 & 99 & 299046 & 166 & 71 & & & & & & & 0149 & 43 & & & & \\
\hline $\mathrm{R}$ & $y k o G$ & $\operatorname{cgR} 0359$ & 54 & 222 & 374324 & 222 & 95 & 299122 & 224 & 76 & & & & & & & 0235 & 41 & 32373 & 43 & & \\
\hline S & $y k o H$ & $\operatorname{cgR} 0360$ & 54 & 489 & 374325 & 489 & 94 & 299123 & 491 & 69 & & & & & & & & & & & & \\
\hline S & $\operatorname{sen} X 3$ & $\operatorname{cgR} 0475$ & 57 & 413 & 374447 & 386 & 96 & 299313 & 413 & 82 & 520071 & 384 & 65 & 844857 & 432 & 54 & 0928 & 51 & 32261 & 49 & 770922 & 55 \\
\hline $\mathrm{R}$ & regX3 & $\operatorname{cgR} 0476$ & 56 & 232 & 374448 & 232 & 93 & 299314 & 232 & 87 & 520072 & 226 & 76 & 844856 & 230 & 70 & 0929 & 72 & 32262 & 70 & 770921 & 78 \\
\hline S & cutS & $\operatorname{cgR} 0540$ & 67 & 344 & & & & & & & & & & & & & & & & & & \\
\hline $\mathrm{R}$ & cutR & $\operatorname{cgR} 0541$ & 66 & 224 & & & & & & & & & & & & & 5468 & 36 & & & 766375 & 51 \\
\hline $\mathrm{R}$ & $\operatorname{cst} A$ & & & & & & & 300245 & 221 & REF & 520143 & 233 & 45 & 844592 & 227 & 47 & & & & & 768832 & 54 \\
\hline S & cstS & & & & & & & 300244 & 395 & REF & 520142 & 408 & 36 & 844593 & 405 & 33 & & & & & 768834 & 36 \\
\hline
\end{tabular}


Table 5. cont.

\begin{tabular}{|c|c|c|c|c|c|c|c|c|c|c|c|c|c|c|c|c|c|c|c|c|c|c|}
\hline Fnct & Gene & $C g \mathrm{R}$ & $G+C$ & Size & $C g \mathrm{~K}$ & Size & Id & $C e$ & Size & Id & $C d$ & Size & Id & $C j$ & Size & Id & Ms & Id & $M t b$ & Id & $N f$ & Id \\
\hline S & narQ & & & & 374641 & 352 & REF & 299058 & 401 & 76 & 520280 & 403 & 45 & & & & & & & & 766586 & 44 \\
\hline $\mathrm{R}$ & narL & $\operatorname{cgR} 0730$ & 59 & 230 & 374642 & 230 & 79 & 299512 & 230 & 70 & 520281 & 231 & 60 & & & & & & & & 766587 & 55 \\
\hline $\mathrm{R}$ & $m t r A$ & $c g R 0863$ & 57 & 226 & 374777 & 226 & 93 & 299658 & 226 & 87 & 520375 & 232 & 76 & 844571 & 225 & 67 & 1877 & 70 & 35020 & 68 & 770338 & 69 \\
\hline $\mathrm{R}$ & $m p r A$ & cgR0988 & 51 & 255 & 374895 & 232 & 90 & 299837 & 233 & 72 & 520533 & 230 & 72 & 844465 & 231 & 66 & 5468 & 65 & 32753 & 64 & 770695 & 65 \\
\hline S & $m p r B$ & cgR0989 & 50 & 479 & 374896 & 455 & 94 & 299838 & 488 & 56 & 520534 & 496 & 44 & 844464 & 517 & 39 & 5467 & 41 & 32754 & 40 & 770694 & 42 \\
\hline S & $y v f T$ & $\operatorname{cgR} 1049$ & 56 & 419 & 374967 & 419 & 90 & 299910 & 419 & 51 & & & & 843797 & 375 & 28 & & & & & & \\
\hline $\mathrm{R}$ & $y v f U$ & $\operatorname{cgR} 1050$ & 57 & 204 & 374968 & 203 & 92 & 299911 & 207 & 69 & & & & 843796 & 200 & 37 & & & & & & \\
\hline $\mathrm{R}$ & $y v q C$ & $\operatorname{cgR} 1838$ & 57 & 210 & 375990 & 210 & 91 & 301671 & 225 & 53 & 521954 & 212 & 50 & 844079 & 216 & 55 & & & & & 769968 & 35 \\
\hline S & $y v q E$ & $\operatorname{cgR} 1839$ & 54 & 383 & 375991 & 377 & 81 & 301672 & 429 & 37 & 521955 & 459 & 37 & 844080 & 364 & 45 & 1491 & 35 & & & & \\
\hline S & fixL & $c g R 2292$ & 48 & 432 & & & & & & & & & & & & & & & & & & \\
\hline $\mathrm{R}$ & fixJ & $\operatorname{cgR} 2299$ & 47 & 205 & & & & & & & & & & & & & & & & & 768547 & 49 \\
\hline S & phoR & $\operatorname{cgR} 2510$ & 56 & 485 & 376573 & 485 & 89 & 301382 & 475 & 66 & 521634 & 519 & 49 & 843214 & 536 & 47 & 5836 & 39 & 32529 & 37 & 766222 & 41 \\
\hline $\mathrm{R}$ & phoP & $c g R 2511$ & 54 & 240 & 376574 & 235 & 98 & 301383 & 240 & 91 & 521635 & 236 & 80 & 843213 & 233 & 73 & 5837 & 68 & 32528 & 67 & 766223 & 63 \\
\hline $\mathrm{R}$ & baeR & $c g R 2566$ & 54 & 241 & 376628 & 241 & 92 & 299167 & 240 & 55 & 519745 & 240 & 57 & 844363 & 240 & 56 & & & & & 770921 & 39 \\
\hline $\mathrm{R}$ & chrA & & & & & & & & & & 522015 & 199 & REF & & & & & & & & & \\
\hline $\mathrm{R}$ & $y f i K$ & & & & 376724 & 206 & REF & 301231 & 267 & 38 & & & & & & & & & & & & \\
\hline S & $y f i J$ & & & & 376723 & 380 & REF & 301230 & 380 & 22 & & & & & & & & & & & & \\
\hline
\end{tabular}


enzyme ( $c g R 1991)$ that forms a putative operon with a regulatory protein of the TetR family ( $c g R 1990)$. Likewise, all corynebacterial trehalose metabolic genes identified previously (Tzvetkov et al., 2003) (treS, cgR2175; treY, cgR2002; treZ, cgR2009; otsA, cgR2531; otsB, cgR2533) are present in C. glutamicum R. Therefore, it is likely that in this bacterium all three trehalose metabolic pathways found in bacteria are enabled [TreS pathway from maltose, TreY/TreZ pathway from $\alpha(1-4)$ glucose polymers, OtsA/OtsB pathway from glucose 6-phosphate and UDP-glucose]. This observation reinforces the view that this non-reducing sugar plays a major physiological role in Actinobacteria as energy storage and as an environmental protectant against various stresses such as low water activity (desiccation, dehydration), external osmolality fluctuations, heat, cold and oxidation. It is also noteworthy that the genes ots $A$ and ots $B$ are part of a putative five-gene operon which is adjacent to a transcriptional regulator of the lacI family (cgR2534) located downstream and in the opposite orientation.

\section{Two-component systems}

Sensing of environmental conditions to ensure variability and adaptability to environmental changes is enabled by two-component systems linked to signal transduction cascades that function via phosphorelays (Taylor \& Zhulin, 1999). Basic two-component systems comprise a membrane-associated sensor kinase that detects external stimuli and a transcriptional regulator that acts upon the cellular machinery to bring about the necessary adaptive changes (Fontan et al., 2004). The genes encoding these two proteins are typically organized in two-gene operons. A similar organization is observed in the genome of $C$. glutamicum $\mathrm{R}$ where $27 \mathrm{ORF}$ are present that share a high level of homology with two-component system genes (Table 5). One orphan regulator (cgR0730), which is dispensable as demonstrated by the absence of phenotypic change upon its deletion (this work), and 13 putative twocomponent systems organized in two-gene operons encoding a sensor kinase and a regulator, have been identified. Despite being absent from the genome of C. glutamicum R, narQ, the putative cognate kinase gene of $c g R 0730$, is present in C. glutamicum ATCC 13032, C. efficiens YS-314 and C. diphtheriae NCTC 13129. On the other hand, orthologues of senX3/regX3, mtrA/mtrB, mprB/mprA and phoR/phoP are present in all the corynebacteria and mycobacteria sequenced to date (Table 5).

The stimuli sensed by most of these two-component systems remain unknown, despite, for example, the fact that the role of citA/citB in the uptake and metabolism of citrate dicarboxylates has been firmly established (Gerharz et al., 2003). In addition, in $M$. tuberculosis, genes under the positive control of PhoP include genes encoding proteins involved in lipid metabolism, cell wall synthesis, membrane transport and oxidative stress response (Fontan et al., 2004). The role of PhoP in adaptation to phosphate-limited conditions has been confirmed in C. glutamicum ATCC 13032 (Kočan et al., 2006). M. tuberculosis phoP mutants have an altered rounded shape and show altered levels of lipoarabinomannan derivatives compared to the wild-type (Fontan et al., 2004), as well as having an impaired ability to synthesize methyl-branched fatty-acid-containing acyltrehaloses (Gonzalo Asensio et al., 2006). Disruption of the putative phoP and phoR genes of C. glutamicum $\mathrm{R}$ demonstrated that these genes are not essential under standard laboratory conditions and that their deletion does not result in any obvious phenotype. Likewise, it has been shown that the $m p r A / m p r B$ gene pair is linked to the sensing of cell-wall- or outer-membrane-related stress (He \& Zahrt, 2005). It is also noteworthy that C. glutamicum $\mathrm{R}$ and $C$. glutamicum ATCC 13032 display, downstream of the putative $m p r A$ - $m p r B$ genes, a putative $p e p D$ gene (respectively, cgR0990 and VIMSS374897), the product of which is a trypsin-like serine protease which is thought to aid in the degradation of misfolded proteins that are generated in response to various stresses. PepD has been demonstrated in M. tuberculosis to be secreted into the culture medium (Skeiky et al., 1999). A similar genetic organization, where the genes mprA-mprB-pepD are part of an operon, has been observed in pathogenic mycobacteria (He \& Zahrt, 2005). The conservation of this gene cluster in both saprophytic and pathogenic organisms suggests that it constitutes an important adaptive mechanism of the bacteria of the Corynebacterineae group. However, none of these genes appears to be essential under laboratory conditions, as demonstrated by the disruption of $m p r A$ and $m p r B$ in $M$. tuberculosis (Zahrt \& Deretic, 2001). Similarly, we achieved the disruption of cgR0988 (mprA), cgR0989 (mprB) and cgR0990 (pepD) in C. glutamicum $\mathrm{R}$ by transposon mutagenesis (this work).

Of these two-component systems, only $m t r A / m t r B$ has been shown to be essential to the growth of M. tuberculosis as demonstrated by unsuccessful attempts to disrupt the $m \operatorname{tr} A$ gene, despite the fact that $m t r B$ appears to be non-essential (Fontan et al., 2004; Zahrt \& Deretic, 2000). The twocomponent system $m$ trA/mtrB is conserved in all actinobacteria (Hoskisson \& Hutchings, 2006) and its regulator is the only response regulator that is induced in M. tuberculosis during macrophage infection, but not in broth culture (Zahrt \& Deretic, 2000). The two-component system MtrA/ MtrB has been shown to strongly influence cellular morphology, antibiotic susceptibility and genetic expression of osmoprotection as demonstrated by the phenotype exhibited by a C. glutamicum ATCC 13032 double mutant (Möker et al., 2004). In C. glutamicum R we succeeded in disrupting either cgR0863 (putative $m t r A$ ) or cgR0864 (putative $m t r B$ ) by inserting a transposon in the central regions of these genes. Neither of the resulting single-gene disruptants showed any significantly altered cellular morphology or altered growth pattern, perhaps indicative of cross-talk between the MtrA and MtrB proteins and one or more other two-component system proteins. The gene immediately downstream of (and overlapping) $m \operatorname{tr} B$ is conserved in all actinobacteria, where it encodes the actinobacteria signature protein LpqB (Gao et al., 2006). 
In the corynebacteria and mycobacteria sequenced to date, $m \operatorname{tr} A$ and $m t r B$ are part of a putative operon that also contains sahH (cgR0861 and VIMSS374775 in C. glutamicum $\mathrm{R}$ and ATCC 13032, respectively), encoding S-adenosylhomocysteine hydrolase, and tmpk (cgR0862 and VIMSS374776, respectively), encoding thymidylate kinase. On the other hand, the cgR0122-cgR0123 two-component system, a putative orthologue of the $y y c F / y y c G$ system of $B$. subtilis that modulates the expression of the ftsAZ operon (Fukuchi et al., 2000), can be deleted from the $C$. glutamicum R genome by excision of SSI-3 without any significant phenotypic change (Suzuki et al., 2005b). Brocker \& Bott (cited in Kočan et al., 2006) suggested that this two-component system is involved in the genetic regulation of copper metabolism. Interestingly, although this two-component system is borne by an SSI in C. glutamicum R, it shows a high level of identity with orthologues found in all the other corynebacteria sequenced to date. On the other hand, its relatively high $\mathrm{G}+\mathrm{C}$ content (greater than $60 \mathrm{~mol} \%$ ) in all corynebacteria sequenced to date would suggest that its acquisition is a recent event in evolutionary terms. Last, the response regulator encoded by gene cgR2566, the product of which shares a high level of homology with the BaeR protein of E. coli, is also conserved in all corynebacteria sequenced to date (Table 5). We did not succeed in disrupting or deleting gene $c g R 2566$ despite being able to mutate cgR 2567 by transposon insertion, its cognate gene encoding a sensor kinase.

Interestingly, two corynebacterial two-component systems appear to be specific to saprophytic corynebacteria. Their highest levels of identity are shared with the putative $B$. subtilis systems $y k o G / y k o H$ (cgR0359/cgR0360) and $y v f T /$ yvfU (cgR1049/cgR1050) (Fabret et al., 1999). Similar to what has been observed in B. subtilis, these genes appear to be non-essential in corynebacteria as demonstrated by the isolation of several transposon mutants of C. glutamicum $\mathrm{R}$ where these genes had been inactivated (this work). However, saprophytic corynebacteria appear to be devoid of $c h r S / c h r A$ or $\operatorname{cstS} /$ cstA orthologues. These latter twocomponent systems, present in both $C$. diphtheriae and $C$. jeikeium, have been linked to haem and haemoglobin sensing (Schmitt, 1999). Nevertheless, ORFs cgR2844 and cgR1838 show low identity but relatively high homology to chrA (67 and 63\%, respectively) and cstA (53\%) from pathogenic corynebacteria. Likewise, corynebacteria appear to be devoid of $\operatorname{devS} / \operatorname{dev} R$ orthologues, which have been linked in $M$. tuberculosis and $M$. bovis with hypoxic dormancy (Boon \& Dick, 2002; Fontan et al., 2004; Saini et al., 2004), albeit that $c g R 2844$ and $c g R 1838$ are 52 and $57 \%$ homologous, respectively, to $M$. bovis $\operatorname{devR}$. Genes $\operatorname{cgR} 2844$ and $c g R 2845$ are dispensable in C. glutamicum $\mathrm{R}$, as demonstrated by their simultaneous deletion via Cre/loxPmediated rearrangements (this work).

Moreover, the genome of C. glutamicum $\mathrm{R}$ reveals the presence of two unique two-component systems, exhibiting high similarity to cutS/cutR of Streptomyces coelicolor involved in negative regulation of actinorhodin synthesis (Hutchings et al., 2004), and to fixL/fixJ of Azorhizobium caulinodans involved in nitrogen fixation in response to lowoxygen conditions (Fischer, 1994). These genes are present on two different SSIs (SSI-5, a region rich in transposase genes, and SSI-9, respectively) (Suzuki et al., 2005a) and are characterized by $\mathrm{G}+\mathrm{C}$ contents that differ significantly from the typical $\mathrm{G}+\mathrm{C}$ content of corynebacterial genomes (Table 5). These observations corroborate the view that these sequences have been acquired by C. glutamicum $\mathrm{R}$ through horizontal transfer events that occurred relatively recently in evolutionary terms. As previously reported, these sequences are dispensable as demonstrated by the absence of a specific phenotype in the corresponding $C$. glutamicum R deletion mutants (Suzuki et al., 2005a). Similarly, C. glutamicum ATCC 13032 exhibits one unique two-component system (VIMSS376724 and VIMSS376723) that shows weak identity to two C. efficiens genes. It is also worth noting that $C$. diphtheriae also possesses a unique two-component system on its chromosome (VIMSS519770 and VIMSS519769), albeit that two similar genes are borne by the $C$. efficiens plasmid pCE3 (Table 5). Likewise, $C$. jeikeium K411 encodes two two-component system genes, $k d p D$ and $k d p E$, putatively involved in turgor pressure sensing and regulation (Hutchings et al., 2004), that are absent from the other corynebacteria sequenced to date, but present in mycobacteria and Streptomyces species (Hutchings et al., 2004).

These different observations promote the view that, except for a few sensor-regulator couples that are highly conserved in Corynebacterineae, the sensing and regulation machinery of corynebacteria is highly plastic. This raises the question whether horizontal transfers of these important adaptation genes, rather than gene decay, has played a major role during the course of evolution of these bacteria. Such a view is consistent with the observed presence in a few corynebacterial strains of two-component systems for which orthologues can only be found in mycobacteria, Streptomyces species or $N$. farcinica, but not in the other corynebacteria sequenced to date. Furthermore, a few of these observed systems either are borne by an episome or are part of an SSI. On the other hand, the overall conservation of these systems between corynebacteria and mycobacteria further validates corynebacteria as important model organisms to contribute to the understanding of the biology of slow-growing pathogenic mycobacteria.

\section{Global differences between saprophytic and pathogenic corynebacteria}

Based on our calculations and model, the presence in the corynebacteria sequenced to date of up to 762 genes identified in COG appears limited to the saprophytes (Table 3). In contrast, pathogenic corynebacteria display fewer candidate pathogen-specific genes (Table 3). For example, we calculated that the saprophytic corynebacteria sequenced to date exhibit approximately $30 \%$ more 
transporters per number of ORFs in their genomes than the pathogenic organisms $C$. diphtheriae and C. jeikeium. This difference constitutes an indication of the relatively greater metabolic versatility of the former organisms. This observation also suggests a higher degree of transporter substrate specificity and a higher number of secondary carriers, since overall the substrate specificities of transport systems of an organism are correlated to its ecological niche and the diversity and relative concentrations of nutrients it encounters (Paulsen et al., 2000).

Likewise, among the genes potentially involved in host interactions, microbiofilm formation, DNA transfer and bacteriophage attachment, C. diphtheriae NCTC 13129 harbours 11 genes putatively encoding fimbrial proteins or fimbria-associated proteins, whereas C. glutamicum $\mathrm{R}$ only exhibits four such genes which are also present in $C$. efficiens (cgR2789, VIMSS301626; cgR2790, VIMSS301627; cgR2791, VIMSS301628; cgR2793, VIMSS301630, respectively). Notably, only one cluster of pili genes is found in saprophytic bacteria, whereas the genome of $C$. diphtheriae NCTC 13129 exhibits three such clusters (Gaspar \& TonThat, 2006). Similarly, C. diphtheriae NCTC 13129 and C. jeikeium K411 harbour, in comparison with C. glutamicum and C. efficiens, a relatively larger number of secreted or surface-anchored proteins, in relation to the ecological niche occupied by these species.

Notably, genes related to amino acid transport and metabolism are fewer in number in pathogenic corynebacteria than in the saprophytic ones (Table 3). In addition to horizontal DNA transfer that has occurred in the saprophytic corynebacteria, this difference has been ascribed to gene decay that has occurred during the course of the evolution of the former organisms (Nishio et al., 2004). Interestingly, this specialization is not the rule in Corynebacterineae, since for example the chromosome sequence of $N$. farcinica reveals that this organism includes many genes for virulence, drug resistance and secondary metabolism. Interestingly, analyses of paralogous protein families suggest that gene duplications have resulted in $N$. farcinica being able to survive not only in soil environments, but also in animal tissues (Ishikawa et al., 2004).

\section{Functional differences between C. glutamicum $R$ and ATCC 13032}

A detailed comparison of the genomic sequence of $C$. glutamicum R with that of ATCC 13032 reveals that only 60 and 189 genes, respectively, are strain-specific. Relatively, both of these strains encode the same number of genes per COG category (Table 3), with a few genes unique to either C. glutamicum strain R or ATCC 13032 when compared to the corynebacteria sequenced to date (Table 3 ). With the exception of sequences from mobile elements, the most striking differences in the number of genes are observed in amino acid transport and metabolism, and secondary metabolite transport and metabolism.

\section{Genes unique to C. glutamicum $\mathbf{R}$}

A total of $9 \%$ (263) of the predicted genes of C. glutamicum ATCC 13032 remain hypothetical or specific to C. glutamicum when compared to C. efficiens YS-314 and C. diphtheriae NCTC 13129 (Kalinowski et al., 2003). It has been suggested that sequencing more than one or two genomes per species is necessary to access bacterial pangenomes (Tettelin et al., 2005). For example, the sequencing of eight strains of Streptococcus agalactiae was found to be sufficient to define the core genome of these organisms with $95 \%$ confidence, whereas each new S. agalactiae genome sequence would reveal an extrapolated 33 new genes, with a $6 \times 10^{-4}$ probability that this number falls to zero. The complete genome sequence of C. glutamicum R reveals 39 genes that to the best of our knowledge have not been previously identified in corynebacteria. In addition to the previously described $\beta$-glucoside phosphotransferase ( $c g R 0436)$ that confers cellobiose utilization properties upon occurrence of a single amino acid substitution (Kotrba et al., 2003), and several mobile-element-derived ORFs (ISCgR3a, IS $C g R 5$, IS $C g R 12 b$, IS $C g R 13 a$, IS $C g R 13 b$ ), C. glutamicum $\mathrm{R}$ notably encodes five novel conserved hypothetical proteins (cgR0052, cgR0067, cgR1134, cgR2375, $c g R 2798$ ), four membrane proteins putatively involved in transport mechanisms (cgR0768, cgR2326, cgR2800, $\operatorname{cgR} 2956)$, as well as four regulatory proteins (cgR0139, cgR0414, cgR1106, cgR2822) in addition to the two twocomponent systems cgR2292/cgR2299 and $c g R 0540 / c g R 0541$ discussed previously. Interestingly, C. glutamicum $\mathrm{R}$ encodes several genes that reflect its ecological niche in soil, as exemplified by a putative tyramine oxidase gene (cgR0016) that could be involved in the degradation of phenethylamines, compounds present in natural environments, or by a putative L-asparaginase ( $c g R 2808)$. As a result, to access the diversity of the metabolism of corynebacteria, a significant number of additional genome sequences would need to be determined.

\section{ACKNOWLEDGEMENTS}

This research was supported by New Energy and Industrial Technology Development Organization (NEDO), Japan.

\section{REFERENCES}

Alm, E. J., Huang, K. H., Price, M. N., Koche, R. P., Keller, K., Dubchak, I. L. \& Arkin, A. P. (2005). The MicrobesOnline Web site for comparative genomics. Genome Res 15, 1015-1022.

Besemer, J., Lomsadze, A. \& Borodovsky, M. (2001). GeneMarkS: a self-training method for prediction of gene starts in microbial genomes. Implications for finding sequence motifs in regulatory regions. Nucleic Acids Res 29, 2607-2618.

Blattner, F. R., Plunkett, G., 3rd, Bloch, C. A., Perna, N. T., Burland, V., Riley, M., Collado-Vides, J., Glasner, J. D., Rode, C. K. \& other authors (1997). The complete genome sequence of Escherichia coli K12. Science 277, 1453-1474.

Bonamy, C., Labarre, J., Reyes, O. \& Leblon, G. (1994). Identification of IS1206, a Corynebacterium glutamicum IS3-related 
insertion sequence and phylogenetic analysis. Mol Microbiol 14, 571-581.

Bonfield, J. K., Smith, K. \& Staden, R. (1995). A new DNA sequence assembly program. Nucleic Acids Res 23, 4992-4999.

Boon, C. \& Dick, T. (2002). Mycobacterium bovis BCG response regulator essential for hypoxic dormancy. J Bacteriol 184, 6760-6767.

Calamita, H., Ko, C., Tyagi, S., Yoshimatsu, T., Morrison, N. E. \& Bishai, W. R. (2005). The Mycobacterium tuberculosis SigD sigma factor controls the expression of ribosome-associated gene products in stationary phase and is required for full virulence. Cell Microbiol 7, 233-244.

Cerdeño-Tárraga, A. M., Efstratiou, A., Dover, L. G., Holden, M. T., Pallen, M., Bentley, S. D., Besra, G. S., Churcher, C., James, K. D. \& other authors (2003). The complete genome sequence and analysis of Corynebacterium diphtheriae NCTC 13129. Nucleic Acids Res 31, 6516-6523.

Chiou, C. Y., Wang, H. H. \& Shaw, G. C. (2002). Identification and characterization of the non-PTS fru locus of Bacillus megaterium ATCC 14581. Mol Genet Genomics 268, 240-248.

Cole, S. T., Brosch, R., Parkhill, J., Garnier, T., Churcher, C., Harris, D., Gordon, S. V., Eiglmeier, K., Gas, S. \& other authors (1998). Deciphering the biology of Mycobacterium tuberculosis from the complete genome sequence. Nature 393, 537-544.

Cole, S. T., Eiglmeier, K., Parkhill, J., James, K. D., Thomson, N. R., Wheeler, P. R., Honore, N., Garnier, T., Churcher, C. \& other authors (2001). Massive gene decay in the leprosy bacillus. Nature 409, 1007-1011.

Delcher, A. L., Harmon, D., Kasif, S., White, O. \& Salzberg, S. L. (1999a). Improved microbial gene identification with GLIMMER. Nucleic Acids Res 27, 4636-4641.

Delcher, A. L., Kasif, S., Fleischmann, R. D., Peterson, J., White, O. \& Salzberg, S. L. (1999b). Alignment of whole genomes. Nucleic Acids Res 27, 2369-2376.

Delcher, A. L., Phillippy, A., Carlton, J. \& Salzberg, S. L. (2002). Fast algorithms for large-scale genome alignment and comparison. Nucleic Acids Res 30, 2478-2483.

Demain, A. L. (2000). Small bugs, big business: the economic power of the microbe. Biotechnol Adv 18, 499-514.

Engels, S., Schweitzer, J. E., Ludwig, C., Bott, M. \& Schäffer, S. (2004). clpC and clpP1P2 gene expression in Corynebacterium glutamicum is controlled by a regulatory network involving the transcriptional regulators $\mathrm{ClgR}$ and $\mathrm{HspR}$ as well as the ECF sigma factor sigmaH. Mol Microbiol 52, 285-302.

Ermolaeva, M. D., White, O. \& Salzberg, S. L. (2001). Prediction of operons in microbial genomes. Nucleic Acids Res 29, 1216-1221.

Ewing, B. \& Green, P. (1998). Base-calling of automated sequencer traces using Phred. II. Error probabilities. Genome Res 8, 186-194.

Ewing, B., Hillier, L., Wendl, M. C. \& Green, P. (1998). Base-calling of automated sequencer traces using Phred. I. Accuracy assessment. Genome Res 8, 175-185.

Fabret, C., Feher, V. A. \& Hoch, J. A. (1999). Two-component signal transduction in Bacillus subtilis: how one organism sees its world. J Bacteriol 181, 1975-1983.

Fischer, H. M. (1994). Genetic regulation of nitrogen fixation in rhizobia. Microbiol Rev 58, 352-386.

Fontan, P. A., Walters, S. \& Smith, I. (2004). Cellular signaling pathways and transcriptional regulation in Mycobacterium tuberculosis: stress control and virulence. Current Sci 86, 122-134.

Fukuchi, K., Kasahara, Y., Asai, K., Kobayashi, K., Moriya, S. \& Ogasawara, N. (2000). The essential two-component regulatory system encoded by $y y c F$ and $y y c G$ modulates expression of the $f t s A Z$ operon in Bacillus subtilis. Microbiology 146, 1573-1583.

Gao, B., Paramanathan, R. \& Gupta, R. S. (2006). Signature proteins that are distinctive characteristics of Actinobacteria and their subgroups. Antonie Van Leeuwenhoek 90, 69-91.

Gaspar, A. H. \& Ton-That, H. (2006). Assembly of distinct pilus structures on the surface of Corynebacterium diphtheriae. J Bacteriol 188, 1526-1533.

Gerharz, T., Reinelt, S., Kaspar, S., Scapozza, L. \& Bott, M. (2003). Identification of basic amino acid residues important for citrate binding by the periplasmic receptor domain of the sensor kinase CitA. Biochemistry 42, 5917-5924.

Glaser, P., Kunst, F., Arnaud, M., Coudart, M. P., Gonzales, W., Hullo, M. F., Ionescu, M., Lubochinsky, B., Marcelino, L. \& other authors (1993). Bacillus subtilis genome project: cloning and sequencing of the $97-\mathrm{kb}$ region from 325 degrees to 333 degrees. Mol Microbiol 10, 371-384.

Goh, E. B., Bledsoe, P. J., Chen, L. L., Gyaneshwar, P., Stewart, V. \& Igo, M. M. (2005). Hierarchical control of anaerobic gene expression in Escherichia coli K-12: the nitrate-responsive NarX-NarL regulatory system represses synthesis of the fumarate-responsive DcuS-DcuR regulatory system. J Bacteriol 187, 4890-4899.

Gonzalo Asensio, J., Maia, C., Ferrer, N. L., Barilone, N., Laval, F., Soto, C. Y., Winter, N., Daffe, M., Gicquel, B. \& other authors (2006). The virulence-associated two-component PhoP-PhoR system controls the biosynthesis of polyketide-derived lipids in Mycobacterium tuberculosis. J Biol Chem 281, 1313-1316.

Gordon, D., Abajian, C. \& Green, P. (1998). Consed: a graphical tool for sequence finishing. Genome Res 8, 195-202.

Grigoriev, A. (1998). Analyzing genomes with cumulative skew diagrams. Nucleic Acids Res 26, 2286-2290.

Hahn, M. Y., Raman, S., Anaya, M. \& Husson, R. N. (2005). The Mycobacterium tuberculosis extracytoplasmic-function sigma factor SigL regulates polyketide synthases and secreted or membrane proteins and is required for virulence. J Bacteriol 187, 7062-7071.

Hansmeier, N., Chao, T. C., Pühler, A., Tauch, A. \& Kalinowski, J. (2006). The cytosolic, cell surface and extracellular proteomes of the biotechnologically important soil bacterium Corynebacterium efficiens YS-314 in comparison to those of Corynebacterium glutamicum ATCC 13032. Proteomics 6, 233-250.

He, H. \& Zahrt, T. C. (2005). Identification and characterization of a regulatory sequence recognized by Mycobacterium tuberculosis persistence regulator MprA. J Bacteriol 187, 202-212.

Hermann, T. (2003). Industrial production of amino acids by coryneform bacteria. J Biotechnol 104, 155-172.

Hermann, T., Pfefferle, W., Baumann, C., Busker, E., Schaffer, S., Bott, M., Sahm, H., Dusch, N., Kalinowski, J. \& other authors (2001). Proteome analysis of Corynebacterium glutamicum. Electrophoresis 22, 1712-1723.

Hoskisson, P. A. \& Hutchings, M. I. (2006). MtrAB-LpqB: a conserved three-component system in actinobacteria? Trends Microbiol 14, 444-449.

Hutchings, M. I., Hoskisson, P. A., Chandra, G. \& Buttner, M. J. (2004). Sensing and responding to diverse extracellular signals? Analysis of the sensor kinases and response regulators of Streptomyces coelicolor A3(2). Microbiology 150, 2795-2806.

Ikeda, M. \& Nakagawa, S. (2003). The Corynebacterium glutamicum genome: features and impacts on biotechnological processes. Appl Microbiol Biotechnol 62, 99-109.

Ikeda, H., Ishikawa, J., Hanamoto, A., Shinose, M., Kikuchi, H., Shiba, T., Sakaki, Y., Hattori, M. \& Omura, S. (2003). Complete 
genome sequence and comparative analysis of the industrial microorganism Streptomyces avermitilis. Nat Biotechnol 21, 526-531.

Inui, M., Murakami, S., Okino, S., Kawaguchi, H., Vertès, A. A. \& Yukawa, H. (2004). Metabolic analysis of Corynebacterium glutamicum during lactate and succinate productions under oxygen deprivation conditions. J Mol Microbiol Biotechnol 7, 182-196.

Ishikawa, J., Yamashita, A., Mikami, Y., Hoshino, Y., Kurita, H., Hotta, K., Shiba, T. \& Hattori, M. (2004). The complete genomic sequence of Nocardia farcinica IFM 10152. Proc Natl Acad Sci U S A 101, 14925-14930.

Jensen-Cain, D. M. \& Quinn, F. D. (2001). Differential expression of sigE by Mycobacterium tuberculosis during intracellular growth. Microb Pathog 30, 271-278.

Kalinowski, J. (2005). The genomes of amino acid-producing corynebacteria. In Handbook of Corynebacterium glutamicum, pp. 37-56. Edited by L. Eggeling \& M. Bott. Boca Raton, FL: CRC Press.

Kalinowski, J., Bathe, B., Bartels, D., Bischoff, N., Bott, M., Burkovski, A., Dusch, N., Eggeling, L., Eikmanns, B. J. \& other authors (2003). The complete Corynebacterium glutamicum ATCC 13032 genome sequence and its impact on the production of Laspartate-derived amino acids and vitamins. J Biotechnol 104, 5-25.

Kobayashi, K., Ehrlich, S. D., Albertini, A., Amati, G., Andersen, K. K., Arnaud, M., Asai, K., Ashikaga, S., Aymerich, S. \& other authors (2003). Essential Bacillus subtilis genes. Proc Natl Acad Sci U S A 100, 4678-4683.

Kočan, M., Schaffer, S., Ishige, T., Sorger-Herrmann, U., Wendisch, V. F. \& Bott, M. (2006). Two-component systems of Corynebacterium glutamicum: deletion analysis and involvement of the PhoS-PhoR system in the phosphate starvation response. J Bacteriol 188, 724-732.

Kotrba, P., Inui, M. \& Yukawa, H. (2003). A single V317A or V317M substitution in Enzyme II of a newly identified $\beta$-glucoside phosphotransferase and utilization system of Corynebacterium glutamicum $\mathrm{R}$ extends its specificity towards cellobiose. Microbiology 149, 1569-1580. Kumagai, H. (2000). Microbial production of amino acids in Japan. Adv Biochem Eng Biotechnol 69, 71-85.

Li, L., Bannantine, J. P., Zhang, Q., Amonsin, A., May, B. J., Alt, D., Banerji, N., Kanjilal, S. \& Kapur, V. (2005). The complete genome sequence of Mycobacterium avium subspecies paratuberculosis. Proc Natl Acad Sci U S A 102, 12344-12349.

Liebl, W. (2001). Corynebacterium - nonmedical. In The Prokaryotes: A Handbook on the Biology of Bacteria, Vol. 3: Archaea and Bacteria: Firmicutes, Actinomycetes, pp. 796-818. Edited by M. Dworkin, S. Falkow, E. Rosenberg, K.-H. Schleifer \& E. Stackebrandt. New York: Springer.

Liebl, W. (2005). Corynebacterium taxonomy. In Handbook of Corynebacterium glutamicum, pp. 9-34. Edited by L. Eggeling \& M. Bott. Boca Raton, FL: CRC Press.

Lowe, T. M. \& Eddy, S. R. (1997). tRNAscan-SE: a program for improved detection of transfer RNA genes in genomic sequence. Nucleic Acids Res 25, 955-964.

Mahillon, J. \& Chandler, M. (1998). Insertion sequences. Microbiol Mol Biol Rev 62, 725-774.

Missiakas, D. \& Raina, S. (1998). The extracytoplasmic function sigma factors: role and regulation. Mol Microbiol 28, 1059-1066.

Möker, N., Brocker, M., Schaffer, S., Krämer, R., Morbach, S. \& Bott, M. (2004). Deletion of the genes encoding the MtrA-MtrB twocomponent system of Corynebacterium glutamicum has a strong influence on cell morphology, antibiotics susceptibility and expression of genes involved in osmoprotection. Mol Microbiol 54, $420-438$
Moon, M. W., Kim, H. J., Oh, T. K., Shin, C. S., Lee, J. S., Kim, S. J. \& Lee, J. K. (2005). Analyses of enzyme II gene mutants for sugar transport and heterologous expression of fructokinase gene in Corynebacterium glutamicum ATCC 13032. FEMS Microbiol Lett 244, 259-266.

Mukherjee, R. \& Chatterji, D. (2005). Evaluation of the role of sigma B in Mycobacterium smegmatis. Biochem Biophys Res Commun 338, 964-972.

Nakamura, Y., Nishio, Y., Ikeo, K. \& Gojobori, T. (2003). The genome stability in Corynebacterium species due to lack of the recombinational repair system. Gene 317, 149-155.

Nishino, K., Honda, T. \& Yamaguchi, A. (2005). Genome-wide analyses of Escherichia coli gene expression responsive to the BaeSR two-component regulatory system. J Bacteriol 187, 1763-1772.

Nishio, Y., Nakamura, Y., Kawarabayasi, Y., Usuda, Y., Kimura, E., Sugimoto, S., Matsui, K., Yamagishi, A., Kikuchi, H. \& other authors (2003). Comparative complete genome sequence analysis of the amino acid replacements responsible for the thermostability of Corynebacterium efficiens. Genome Res 13, 1572-1579.

Nishio, Y., Nakamura, Y., Usuda, Y., Sugimoto, S., Matsui, K., Kawarabayasi, Y., Kikuchi, H., Gojobori, T. \& Ikeo, K. (2004). Evolutionary process of amino acid biosynthesis in Corynebacterium at the whole genome level. Mol Biol Evol 21, 1683-1691.

Paulsen, I. T., Nguyen, L., Sliwinski, M. K., Rabus, R. \& Saier, M. H., Jr (2000). Microbial genome analyses: comparative transport capabilities in eighteen prokaryotes. J Mol Biol 301, 75-100.

Raman, S., Song, T., Puyang, X., Bardarov, S., Jacobs, W. R., Jr \& Husson, R. N. (2001). The alternative sigma factor SigH regulates major components of oxidative and heat stress responses in Mycobacterium tuberculosis. J Bacteriol 183, 6119-6125.

Rice, P., Longden, I. \& Bleasby, A. (2000). EMBOss: the European Molecular Biology Open Software Suite. Trends Genet 16, 276-277.

Saier, M. H., Jr (2002). The Bacterial Phosphotransferase System. Norwich: Horizon.

Saini, D. K., Malhotra, V., Dey, D., Pant, N., Das, T. K. \& Tyagi, J. S. (2004). DevR-DevS is a bona fide two-component system of Mycobacterium tuberculosis that is hypoxia-responsive in the absence of the DNA-binding domain of DevR. Microbiology 150, 865-875.

Salzberg, S. L., Delcher, A. L., Kasif, S. \& White, O. (1998). Microbial gene identification using interpolated Markov models. Nucleic Acids Res 26, 544-548.

Sambrook, J., Fritsch, E. F. \& Maniatis, T. (1989). Molecular Biology: a Laboratory Manual, 2nd edn. Cold Spring Harbor, New York: Cold Spring Harbor Laboratory.

Schmitt, M. P. (1999). Identification of a two-component signal transduction system from Corynebacterium diphtheriae that activates gene expression in response to the presence of heme and hemoglobin. J Bacteriol 181, 5330-5340.

Shen, X. H., Jiang, C. Y., Huang, Y., Liu, Z. P. \& Liu, S. J. (2005). Functional identification of novel genes involved in the glutathioneindependent gentisate pathway in Corynebacterium glutamicum. Appl Environ Microbiol 71, 3442-3452.

Shilo, M. \& Wolman, B. (1958). Activities of bacterial levans and of lipopolysaccharides in the processes of inflammation and infection. Br J Exp Pathol 39, 652-660.

Skeiky, Y. A., Lodes, M. J., Guderian, J. A., Mohamath, R., Bement, T., Alderson, M. R. \& Reed, S. G. (1999). Cloning, expression, and immunological evaluation of two putative secreted serine protease antigens of Mycobacterium tuberculosis. Infect Immun 67, 3998-4007.

Stackebrandt, E. \& Woese, C. R. (1981). The evolution of prokaryotes. In Molecular and Cellular Aspects of Microbial Evolution, pp. 1-31. Edited by M. J. Carlile, J. F. Collins \& B. E. B. Moseley. Cambridge: Cambridge University Press. 
Stackebrandt, E., Rainey, F. A. \& Ward-Rainey, N. L. (1997). Proposal for a new hierarchical classification system, Actinobacteria classis nov. Int J Syst Bacteriol 47, 479-491.

Staden, R. (1996). The Staden sequence analysis package. Mol Biotechnol 5, 233-241.

Stecker, C., Johann, A., Herzberg, C., Averhoff, B. \& Gottschalk, G. (2003). Complete nucleotide sequence and genetic organization of the 210-kilobase linear plasmid of Rhodococcus erythropolis BD2. $J$ Bacteriol 185, 5269-5274.

Stothard, P. \& Wishart, D. S. (2005). Circular genome visualization and exploration using CGView. Bioinformatics 21, 537-539.

Sun, R., Converse, P. J., Ko, C., Tyagi, S., Morrison, N. E. \& Bishai, W. R. (2004). Mycobacterium tuberculosis ECF sigma factor sigC is required for lethality in mice and for the conditional expression of a defined gene set. Mol Microbiol 52, 25-38.

Suzuki, N., Okayama, S., Nonaka, H., Tsuge, Y., Inui, M. \& Yukawa, H. (2005a). Large-scale engineering of the Corynebacterium glutamicum genome. Appl Environ Microbiol 71, 3369-3372.

Suzuki, N., Tsuge, Y., Inui, M. \& Yukawa, H. (2005b). Cre/loxPmediated deletion system for large genome rearrangements in Corynebacterium glutamicum. Appl Microbiol Biotechnol 67, 225-233.

Suzuki, N., Okai, N., Nonaka, H., Tsuge, Y., Inui, M. \& Yukawa, H. (2006). High throughput transposon mutagenesis of Corynebacterium glutamicum and construction of a single-gene disruptant mutant library. Appl Environ Microbiol 72, 3750-3755.

Tatusov, R. L., Koonin, E. V. \& Lipman, D. J. (1997). A genomic perspective on protein families. Science 278, 631-637.

Tauch, A., Gotker, S., Puhler, A., Kalinowski, J. \& Thierbach, G. (2002). The 27.8-kb R-plasmid pTET3 from Corynebacterium glutamicum encodes the aminoglycoside adenyltransferase gene cassette aadA9 and the regulated tetracycline efflux system Tet 33 flanked by active copies of the widespread insertion sequence IS6100. Plasmid 48, 117-129.

Tauch, A., Puhler, A., Kalinowski, J. \& Thierbach, G. (2003). Plasmids in Corynebacterium glutamicum and their molecular classification by comparative genomics. J Biotechnol 104, 27-40.

Tauch, A., Kaiser, O., Hain, T., Goesmann, A., Weisshaar, B., Albersmeier, A., Bekel, T., Bischoff, N., Brune, I. \& other authors (2005). Complete genome sequence and analysis of the multiresistant nosocomial pathogen Corynebacterium jeikeium K411, a lipid-requiring bacterium of the human skin flora. J Bacteriol 187, 4671-4682.

Taylor, B. L. \& Zhulin, I. B. (1999). PAS domains: internal sensors of oxygen, redox potential, and light. Microbiol Mol Biol Rev 63, 479-506.

Tettelin, H., Masignani, V., Cieslewicz, M. J., Donati, C., Medini, D., Ward, N. L., Angiuoli, S. V., Crabtree, J., Jones, A. L. \& other authors
(2005). Genome analysis of multiple pathogenic isolates of Streptococcus agalactiae: implications for the microbial 'pan-genome'. Proc Natl Acad Sci U S A 102, 13950-13955.

Tzvetkov, M., Klopprogge, C., Zelder, O. \& Liebl, W. (2003). Genetic dissection of trehalose biosynthesis in Corynebacterium glutamicum: inactivation of trehalose production leads to impaired growth and an altered cell wall lipid composition. Microbiology 149, 1659-1673.

Vertès, A. A., Hatakeyama, K., Inui, M., Kobayashi, M., Kurusu, Y. \& Yukawa, H. (1993a). Replacement recombination in coryneform bacteria: high efficiency integration requirement for non-methylated plasmid DNA. Biosci Biotechnol Biochem 57, 2036-2038.

Vertès, A. A., Inui, M., Kobayashi, M., Kurusu, Y. \& Yukawa, H. (1993b). Presence of $m r r-$ and $m c r$-like restriction systems in coryneform bacteria. Res Microbiol 144, 181-185.

Vertès, A. A., Inui, M. \& Yukawa, H. (2005). Manipulating corynebacteria from individual genes to chromosome. Appl Environ Microbiol 71, 7633-7642.

von Graevenitz, A. \& Bernard, K. (2001). The genus Corynebacterium - medical. In The Prokaryotes: A Handbook on the Biology of Bacteria, Vol. 3: Archaea and Bacteria: Firmicutes, Actinomycetes, pp. 819-842. Edited by M. Dworkin, S. Falkow, E. Rosenberg, K.-H. Schleifer \& E. Stackebrandt. New York: Springer.

Waagmeester, A., Thompson, J. \& Reyrat, J. M. (2005). Identifying sigma factors in Mycobacterium smegmatis by comparative genomic analysis. Trends Microbiol 13, 505-509.

Winnen, B., Felce, J. \& Saier, M. H., Jr (2005). Genomic analyses of transporter proteins in Corynebacterium glutamicum and Corynebacterium efficiens. In Handbook of Corynebacterium glutamicum, pp. 149-186. Edited by L. Eggeling \& M. Bott. Boca Raton, FL: CRC Press.

Yukawa, H., Inui, M. \& Vertès, A. A. (2007). Genomes and genomelevel engineering of amino-acid producing bacteria. In Amino Acid Biosynthesis - Pathways, Regulation and Metabolic Engineering. Edited by V. F. Wendisch. Heidleberg: Springer (in press).

Zahrt, T. C. \& Deretic, V. (2000). An essential two-component signal transduction system in Mycobacterium tuberculosis. J Bacteriol 182, 3832-3838.

Zahrt, T. C. \& Deretic, V. (2001). Mycobacterium tuberculosis signal transduction system required for persistent infections. Proc Natl Acad Sci U S A 98, 12706-12711.

Zhang, R. \& Zhang, C. T. (2004). A systematic method to identify genomic islands and its applications in analyzing the genomes of Corynebacterium glutamicum and Vibrio vulnificus CMCP6 chromosome I. Bioinformatics 20, 612-622.

Edited by: C. W. Chen 